\title{
Aerosol and physical atmosphere model parameters are both important sources of uncertainty in aerosol ERF
}

\author{
Leighton A. Regayre $^{1}$, Jill S. Johnson ${ }^{1}$, Masaru Yoshioka ${ }^{1}$, Kirsty J. Pringle ${ }^{1}$, David M. H. Sexton ${ }^{2}$, Ben B. B. Booth ${ }^{2}$, \\ Lindsay A. Lee ${ }^{1}$, Nicolas Bellouin ${ }^{3}$, and Kenneth S. Carslaw ${ }^{1}$ \\ ${ }^{1}$ Institute for Climate and Atmospheric Science, School of Earth and Environment, University of Leeds, Leeds, LS2 9JT, UK \\ ${ }^{2}$ UK Hadley Centre Met Office, Exeter, Fitzroy Road, Exeter, Devon, EX1 3PB, UK \\ ${ }^{3}$ Department of Meteorology, School of Mathematical \& Physical Sciences, Faculty of Science, \\ University of Reading, Reading, RG6 6BB, UK
}

Correspondence: Leighton Regayre (1.a.regayre@ leeds.ac.uk)

Received: 15 February 2018 - Discussion started: 1 March 2018

Revised: 6 June 2018 - Accepted: 15 June 2018 - Published: 13 July 2018

\begin{abstract}
Changes in aerosols cause a change in net topof-the-atmosphere (ToA) short-wave and long-wave radiative fluxes; rapid adjustments in clouds, water vapour and temperature; and an effective radiative forcing (ERF) of the planetary energy budget. The diverse sources of model uncertainty and the computational cost of running climate models make it difficult to isolate the main causes of aerosol ERF uncertainty and to understand how observations can be used to constrain it. We explore the aerosol ERF uncertainty by using fast model emulators to generate a very large set of aerosolclimate model variants that span the model uncertainty due to 27 parameters related to atmospheric and aerosol processes. Sensitivity analyses shows that the uncertainty in the ToA flux is dominated (around $80 \%$ ) by uncertainties in the physical atmosphere model, particularly parameters that affect cloud reflectivity. However, uncertainty in the change in ToA flux caused by aerosol emissions over the industrial period (the aerosol ERF) is controlled by a combination of uncertainties in aerosol (around $60 \%$ ) and physical atmosphere (around $40 \%$ ) parameters. Four atmospheric and aerosol parameters account for around $80 \%$ of the uncertainty in short-wave ToA flux (mostly parameters that directly scale cloud reflectivity, cloud water content or cloud droplet concentrations), and these parameters also account for around $60 \%$ of the aerosol ERF uncertainty. The common causes of uncertainty mean that constraining the modelled planetary brightness to tightly match satellite observations changes the lower $95 \%$ credible aerosol ERF value from -2.65 to $-2.37 \mathrm{~W} \mathrm{~m}^{-2}$. This suggests the strongest forcings
\end{abstract}

(below around $-2.4 \mathrm{~W} \mathrm{~m}^{-2}$ ) are inconsistent with observations. These results show that, regardless of the fact that the ToA flux is 2 orders of magnitude larger than the aerosol ERF, the observed flux can constrain the uncertainty in ERF because their values are connected by constrainable process parameters. The key to reducing the aerosol ERF uncertainty further will be to identify observations that can additionally constrain individual parameter ranges and/or combined parameter effects, which can be achieved through sensitivity analysis of perturbed parameter ensembles.

\section{Introduction}

Large aerosol radiative forcing uncertainty has persisted through all Intergovernmental Panel on Climate Change assessment reports since 1996 despite substantial developments in climate model complexity (Flato et al., 2013, Sect. 9.1.3), numerous intercomparison projects (Randles et al., 2013; Tsigaridis et al., 2014; Kim et al., 2014; Mann et al., 2014; Pan et al., 2015; Lacagnina et al., 2015; Kipling et al., 2016; Ghan et al., 2016; Koffi et al., 2016) and enormous investments in observing systems (Khain et al., 2000; Lacagnina et al., 2015; Seinfeld et al., 2016; Reddington et al., 2017). Reducing aerosol forcing uncertainty has therefore proven to be one of the most challenging and persistent problems in atmospheric science.

Reduction of uncertainty in aerosol effective radiative forcing (ERF) is an important objective, not least because it 
would improve climate change projections (Andreae et al., 2005; Myhre et al., 2013; Collins et al., 2013; Tett et al., 2013; Seinfeld et al., 2016). An improved understanding of the causes of uncertainty would also help to prioritise model developments, suggest fruitful analyses across multiple models and point to potential new observations to constrain the uncertainties. However, the task remains challenging for multiple reasons. For example, aerosol ERF is usually quantified with reference to a period pre-dating the satellite era (usually 1850 or 1750), meaning it is not a directly observable quantity. Satellite-derived observations of present-day (PD) aerosol-cloud relationships have the potential to constrain the aerosol ERF uncertainty but require an improved understanding of aerosol changes over the industrial period (Gryspeerdt et al., 2017). Some of the ERF uncertainty might therefore be irreducible unless pristine present-day environments are shown to be a good proxy for pre-industrial conditions (Carslaw et al., 2013; Hamilton et al., 2014; Carslaw et al., 2017). Furthermore, aerosol ERF depends on many poorly understood interactions of aerosols with components of the physical climate system. Important sources of uncertainty are known to be aerosol emission fluxes (Granier et al., 2011), representations of complex sub-grid processes such as clouds (Haerter et al., 2009; Lohmann and Ferrachat, 2010; Guo et al., 2013; Gettleman et al., 2013; Golaz et al., 2013; Neubauer et al., 2014; Lohmann, 2017), precipitation responses (Tost et al., 2010; Croft et al., 2012; Michibata and Takemura, 2015), aerosol processes (Croft et al., 2012; Textor et al., 2006, 2007; Storelvmo et al., 2009; Kasoar et al., 2016), radiation calculations (Stier et al., 2013; Wilcox et al., 2015) and subsequent feedbacks on atmospheric dynamics (Booth et al., 2012; Bollasina et al., 2013; Kirtman et al., 2013; Villarini and Vecchi, 2013; Allen et al., 2014) and surface temperatures (Golaz et al., 2013).

Our intention here is to constrain aerosol ERF uncertainty by pursuing a "bottom-up" approach that explores the underlying process uncertainty. This approach provides a set of observationally plausible model variants with which near-term climate simulations could be performed. Although a lower limit to the global mean aerosol ERF might be found using a "top-down" approach and historical temperature trends (Stevens, 2015), inferences made about the climate system are very sensitive to the simplifying assumptions that are made in top-down approaches (Knutti et al., 2008; Kretzschmar et al., 2017). More importantly, such methods do not provide a model with which to make improved climate projections, and they provide no information about regional variations in forcing, which are known to be important drivers of climate variability (Chalmers et al., 2012; Dunstone et al., 2013; Shindell et al., 2013; Kirtman et al., 2013; Bollasina et al., 2013). Therefore, bottom-up methods that quantify aerosol ERF using global climate models whose performance and uncertainty are constrained by observations are required.

Multi-model studies (or model intercomparison projects, MIPs) can provide some information about ERF uncertainty because a set of models with different dynamical cores and physical process parametrisations produces a range of aerosol responses. However, such opportunistic sampling has three main disadvantages. Firstly, inter-model comparisons often include models with vastly different degrees of complexity (Collins et al., 2013). For example, aerosol indirect effects are not represented in many of the models included in such studies, and this artificially inflates multi-model forcing uncertainty (Bellucci et al., 2017). Secondly, multiple members of an inter-model comparison will share key modules and behaviours (Pennell and Reichler, 2010; Collins et al., 2010; Knutti et al., 2013). This leads to compensating effects between groups of models with shared structural errors that cause the multi-model mean to outperform the majority of individual models across a range of climate metrics (Rougier, 2016). Thirdly, a small set of models (perhaps around 20) cannot possibly sample the effects of dozens of interacting uncertain processes in the individual models (Carslaw et al., 2018). Therefore, inter-model comparisons do not provide statistically representative samples (Sexton et al., 2012; Knutti et al., 2013; Collins et al., 2013), making it difficult to draw inferences about the causes of aerosol ERF uncertainty and the robustness of any observational constraint. Leading experts subjectively assess the uncertainty in aerosol forcing as being larger than that quantified by multi-model studies (Morgan et al., 2006).

A complementary approach to exploring aerosol ERF uncertainty in multiple models is to systematically explore the uncertainty in underlying parameters and processes within a single model. Much progress has been made in understanding the causes of uncertainty in state variables related to aerosol ERF, such as cloud-active aerosol concentrations (Lee et al., 2011, 2012, 2013; Samset et al., 2014; Mann et al., 2014; Shrivastava et al., 2016; Kipling et al., 2016), precipitation (Lebo and Feingold, 2014; Qian et al., 2015; Johnson et al., 2015) and top-of-the-atmosphere (ToA) radiative fluxes (Shiogama et al., 2012; Zhau et al., 2013; Randles et al., 2013). Furthermore, important sources of aerosol forcing uncertainty (in the absence of rapid atmospheric adjustments) have been identified (Schulz et al., 2006; Haerter et al., 2009; Lohmann and Ferrachat, 2010; Carslaw et al., 2013; Myhre et al., 2013; Regayre et al., 2014, 2015). However, no study has comprehensively explored aerosol ERF uncertainty in a model that accounts for rapid atmospheric adjustments. Studies that do include rapid adjustments (e.g. Gettleman, 2015) rely on one-at-a-time experiments (where individual parameters or model structures are perturbed in isolation), which do a poor job of sampling the model uncertainty because they neglect important parameter interactions (Pianosi et al., 2016).

Here we present a perturbed parameter ensemble of the HadGEM3-GA4-UKCA global aerosol-chemistry-climate model and use model emulation (Lee et al., 2013) to enable the combined effects of uncertainties in 27 aerosol, cloud and other atmospheric model processes to be quanti- 
fied. Compared to our previous studies (Carslaw et al., 2013; Regayre et al., 2014, 2015) we take a more holistic approach to exploring model forcing uncertainty here by accounting for the uncertainty in cloud and other physical atmospheric processes, as well as the uncertainties in the aerosol component of the model. We also explore for the first time the uncertainty in aerosol ERF (including rapid atmospheric adjustments to aerosols) and in the components of ERF from aerosol-radiation interactions $\left(\mathrm{ERF}_{\mathrm{ARI}}\right)$ and aerosol-cloud interactions $\left(\mathrm{ERF}_{\mathrm{ACI}}\right)$. Other attempts to quantify the uncertainty in the ToA radiative flux caused by aerosols (Tett et al., 2013; Shiogama et al., 2012) explored only the current state of the atmosphere and not how it changes over time.

The main questions we address in this paper are as follows. (1) How much of the uncertainty in aerosol ERF is caused by aerosol processes and how much by physical atmosphere processes? The answer is important because it will tell us how the tuning of model processes apparently unrelated to aerosols might inadvertently affect the aerosol ERF that models calculate. (2) What are the processes that cause uncertainty in the aerosol ERF, and to what extent do they also affect the observable radiative state of the atmosphere? This is important because aerosol ERF uncertainty will only be effectively constrained by observations if the uncertainty in both the ERF and the observations is driven by the same uncertain processes (Lee et al., 2016). (3) How much does tuning the radiative state of the model (i.e. ruling out implausible model settings) affect the range of aerosol ERFs? The effect of tuning of, for example, ToA radiative flux (Lohmann and Ferrachat, 2010; Mauritsen et al., 2012) on the aerosol ERF is not normally considered. However, we show that many model variants (and parts of uncertain parameter space) can be ruled out using ToA flux observations and that such state variable observations can play an important part in reducing the overall uncertainty in aerosol ERF. The results from this paper inform our more comprehensive effort to constrain aerosol ERF uncertainty using multiple observational quantities (Johnson et al., 2018).

In Sect. 2 we outline our methodology; then in Sect. 3.1 we quantify the magnitude of the uncertainty in aerosol ERF, $E F_{A R I}$ and $E_{\text {RF }}$ ACI through comprehensive sampling of model parameter uncertainty. We then analyse the main causes of uncertainty in aerosol ERF over multi-century and multi-decadal periods in Sect. 3.2 and the causes of ToA radiative flux uncertainty in Sect. 3.3 using sensitivity analysis techniques (Sect. 2). We also quantify the relative importance of atmospheric and aerosol parameters as sources of uncertainty in aerosol ERF and ToA radiative flux in Sect. 3.3. In Sect. 3.4 we identify the main causes of uncertainty in aerosol ERF and its components within 11 climatically important regions. Following Lohmann and Ferrachat (2010), we then explore how constraint of the model state using present-day ToA flux observations influences the plausible range of aerosol ERF (Sect. 3.5.1 and 3.5.4). We show that, whilst the relationships between the important driving parameters and individual parameter ranges are well constrained by ToA flux measurements (Sect. 3.5.2 and 3.5.3), the range of credible aerosol ERFs is only moderately $(10 \%)$ constrained. We investigate the causes of the modest constraint in Sects. 3.5.2, 3.5.3 and 4.

\section{Methods}

\subsection{Set-up of the HadGEM-UKCA aerosol-climate model}

We used the UK Hadley Centre Met Office Unified Model (HadGEM3, 2017) including release version 8.4 of the UK Chemistry and Aerosol (UKCA) model, within which the evolution of particle size distribution and sizeresolved chemical composition of aerosols are calculated using the GLObal Model of Aerosol Processes (GLOMAP; Spracklen et al., 2005; Mann et al., 2010). The model has a $1.25^{\circ} \times 1.875^{\circ}$ horizontal resolution and 85 vertical hybrid pressure levels. The aerosol size distribution is defined by seven log-normal modes: one soluble nucleation mode as well as soluble and insoluble Aitken, accumulation and coarse modes. The aerosol chemical components are sulfate, sea salt, black carbon, particulate organic carbon and dust. Secondary organic aerosol material is produced from the first-stage oxidation products of biogenic monoterpenes under the assumption of zero vapour pressure. After kinetic condensation onto existing aerosols, organic aerosols (primary and secondary) are treated as one chemical tracer.

The GLOMAP model resolves new particle formation, particle coagulation, gas-to-particle transfer, cloud processing (aqueous chemistry) and the deposition of gases and aerosols. Sulfate particles form by binary homogeneous nucleation (Vehkamäki et al., 2002) throughout the atmosphere and by organically mediated nucleation (Metzger et al., 2010) in the boundary layer. The activation of aerosol particles into cloud droplets is calculated using distributions of sub-grid vertical velocities (West et al., 2014), and the removal of cloud droplets by autoconversion into raindrops is calculated by the physical atmosphere model. Aerosol removal by impaction scavenging of falling raindrops (within and below clouds) in the physical atmosphere model depends partly on the collocation of clouds and precipitation (Boutle et al., 2014). Soluble particles grow according to the relative atmospheric humidity using composition-dependent hygroscopicity factors $(\kappa)$ in accordance with "Köhler theory" (Petters and Kreidenweis, 2007).

Successive versions of the GLOMAP model have been widely evaluated against global measurements of particle number concentration (Spracklen et al., 2010; Reddington et al., 2011), chemical compositions (Spracklen et al., 2011b; Schmidt et al., 2011; Browse et al., 2012) and cloud active aerosol concentrations (Korhonen et al., 2008; Spracklen et al., 2011a; Pringle et al., 2012). The HadGEM models are 
subject to constant monitoring for ongoing use in numerical weather prediction and have informed successive Coupled Model Inter-comparison Project (CMIP) experiments (Taylor et al., 2012). HadGEM capably represents changes in cloud regime (Nam et al., 2012) - one of the requirements for simulating rapid adjustments to aerosol perturbations (Stevens and Feingold, 2009; Zhang et al., 2016). Cloud water responses to aerosols may be too strong in the HadGEM model because the current model version does not represent enhanced drying in polluted clouds (Toll et al., 2017). However, over multiple cloud regimes the cloud water response is not of a sufficient magnitude to be climatically important (Malavelle et al., 2017).

Anthropogenic emission scenarios prepared for the Atmospheric Chemistry and Climate Model Inter-comparison Project (ACCMIP; Lamarque et al., 2010) and prescribed in some of the CMIP Phase 5 experiments (Taylor et al., 2012) are prescribed here. Carbonaceous aerosol emissions from fires were prescribed using a 10-year average of 2002 to 2011 monthly mean data from the Global Fire and Emissions Database (GFED3; van der Werf et al., 2010).

Model horizontal winds were relaxed (nudged) towards winds from the European Centre for Medium-Range Weather Forecasts (ECMWF) ERA-Interim reanalysis above around $2 \mathrm{~km}$. Nudging of atmospheric states is used primarily to evaluate output from global models (Telford et al., 2008) or to ensure that pairs of simulations have near-identical atmospheric states, so that aerosol and/or chemistry perturbations can be applied and their effects quantified using single realisations of each simulation. In "free-running" (non-nudged) simulations radiative fluxes need to be averaged over many decades in order to produce signals stronger than the noise resulting from internal variability (Kooperman et al., 2012). Nudging to horizontal winds above around $2 \mathrm{~km}$ forces synoptic-scale dynamical features to be consistent across the ensemble, whilst allowing boundary layer atmospheric adjustments in response to changes in aerosols to be affected by the parameter perturbations.

Each simulation was subject to a 7-month spin-up period from a consistent starting simulation, with parameters set to their median values for the first 4 months. Parameter perturbations were applied during the final 3 months of the spin-up period, after which a full year of data was produced for each ensemble member. Aerosol ERF is calculated as the difference in net ToA short-wave plus long-wave radiative fluxes between pairs of simulations with identical parameter settings but distinct prescriptions of anthropogenic emissions (1850, 1978 and 2008). The aerosol ERF and its components were calculated based on the method of Ghan (2013).

\subsection{Parameter sampling}

The 27 parameters perturbed in the ensemble, as well as the roles they play in the model, are presented in Table 1. We perturbed nine parameters in the physical atmosphere model known to affect the properties and distribution of clouds and humidity within the boundary layer (atmospheric parameters; Sexton et al., 2018) in combination with 18 aerosol emission, deposition and process parameters (aerosol parameters) known to affect cloud droplet number concentrations (Lee et al., 2013) and/or aerosol cloud-albedo effect forcing (the $\mathrm{ERF}_{\mathrm{ACI}}$ without accounting for rapid adjustments) at the global (Carslaw et al., 2013; Regayre et al., 2014) and/or regional scale (Regayre et al., 2015). Some parameters have been included in the ensemble because they represent model structural advances with inherent process uncertainty (Yoshioka et al., 2018).

We did not attempt to include an exhaustive set of uncertain parameters in the experimental design. Current supercomputing resources are too valuable to justify an uninformed, exhaustive exploration of model uncertainty. Instead, we used one-at-a-time perturbation screening experiments (not shown) to identify the parameters most likely to influence radiative forcing within the model. The parameters included in the preliminary screening process were identified by model domain experts as the key parameters within individual model schemes (e.g. cloud microphysics) and/or model processes (e.g. cloud droplet activation) with the potential to significantly affect aerosol ERF. Our results may change slightly with the inclusion of additional parameters. However, we went through a thorough parameter screening and prioritisation process, so we consider the parametric uncertainty to be close to an upper limit. Furthermore, with many possible opportunities for parameter compensation, additional parameters only very gradually increase the overall uncertainty.

The parameters we perturb here are likely to have readily identifiable counterparts in other climate models. All global climate models have similarities because they describe the same physical processes; although process parametrisations can differ between models, they often share common biases when compared to measurements (Knutti et al., 2013). Therefore, our aim to identify the main causes of aerosol ERF uncertainty in the HadGEM model (Sect. 3) will provide valuable clues for reducing the aerosol ERF uncertainty in other models.

\subsubsection{Definition of atmospheric parameters}

\section{Rad_Mcica_Sigma}

The fractional standard deviation of the sub-grid cloud condensate as seen by radiation. This parameter controls the inhomogeneity of cloud condensate within vertically overlapping sub-grid clouds (Räisänen et al., 2004), which is used to calculate cloud radiative fluxes. Higher values of Rad_Mcica_Sigma increase cloud condensate inhomogeneity and hence reduce cloud albedo (because of the non-linear relationship between albedo and cloud condensate; Barker and Räisänen, 2005). Atmospheric temperature profiles re- 
Table 1. Descriptions of the perturbed parameters. Parameters are grouped according to their source within the model as either "Atm" for atmospheric or "Aer" for aerosol parameters.

\begin{tabular}{|c|c|c|c|}
\hline Name & Source & Description & PDF \\
\hline Rad_Mcica_Sigma & Atm & $\begin{array}{l}\text { Fractional standard deviation of sub-grid } \\
\text { condensate seen by radiation }\end{array}$ & Trapezoid $(0.1,0.4,1.5,2.2,2,2)$ \\
\hline C_R_Correl & Atm & Cloud and rain sub-grid horizontal spatial correlation & Trapezoid $(0.0,0.6,0.9,1.0,1.8,1.1,1.5)$ \\
\hline Niter_BS & Atm & Number of microphysics iteration sub-steps & Uniform $(5,20)$ \\
\hline Ent_Fac_Dp & Atm & Entrainment amplitude scale factor & Trapezoid $(0,0.5,2,4,2,2)$ \\
\hline Amdet_Fac & Atm & Mixing detrainment rate scale factor & Trapezoid $(0,0.5,10.0,15.0,2,2)$ \\
\hline Dbsdtbs_Turb_0 & Atm & Cloud erosion rate $\left(\mathrm{s}^{-1}\right)$ & $\begin{array}{l}\text { Trapezoid }\left(0,1 \times 10^{-4}, 5 \times 10^{-4}\right. \\
\left.1 \times 10^{-3}, 2,2\right)\end{array}$ \\
\hline Mparwtr & Atm & $\begin{array}{l}\text { Maximum value of function controlling convective } \\
\text { parcel maximum condensate }\end{array}$ & $\begin{array}{l}\text { Trapezoid }\left(1 \times 10^{-3}, 1 \times 10^{-3}\right. \\
\left.1.5 \times 10^{-3}, 2 \times 10^{-3}, 2,2\right)\end{array}$ \\
\hline Dec_Thres_Cld & Atm & Threshold for cloudy boundary layer decoupling & Trapezoid $(0.01,0.011,0.1,0.8,2,4,4)$ \\
\hline Fac_Qsat & Atm & $\begin{array}{l}\text { Rate of change in convective parcel maximum } \\
\text { condensate }\end{array}$ & Uniform $(0.25,1)$ \\
\hline Ageing & Aer & $\begin{array}{l}\text { Ageing of hygrophobic aerosols } \\
\text { (no. of monolayers of organic material) }\end{array}$ & Trapezoid $(0.3,1,5,10,2,2)$ \\
\hline Cloud_pH & Aer & $\mathrm{pH}$ of cloud droplets & Trapezoid $(4.6,5.3,6.3,7,4,2)$ \\
\hline Carb_BB_Ems & Aer & Carbonaceous biomass burning emission scale factor & Trapezoid $(0.25,0.8,2.2,4,2,2)$ \\
\hline Carb_BB_Diam & Aer & Carbonaceous biomass burning emission diameter $(\mathrm{nm})$ & Trapezoid $(90,160,240,300,2,2)$ \\
\hline Sea_Spray & Aer & Sea spray aerosol emission scale factor & Trapezoid $(0.125,0.6,3,8,4,3)$ \\
\hline Anth_SO2 & Aer & Anthropogenic $\mathrm{SO}_{2}$ emission scale factor & Trapezoid $(0.6,0.81,1.09,1.5,2,2)$ \\
\hline Volc_SO2 & Aer & Volcanic $\mathrm{SO}_{2}$ emission scale factor & Trapezoid $(0.71,0.99,1.7,2.38,4,1.1)$ \\
\hline BVOC_SOA & Aer & $\begin{array}{l}\text { Biogenic secondary aerosol formation from volatile } \\
\text { organic compound scale factor }\end{array}$ & Trapezoid $(0.81,1.08,3.5,5.4,3,3)$ \\
\hline DMS & Aer & $\begin{array}{l}\text { Dimethylsulfide surface ocean } \mathrm{SO}_{2} \text { concentration } \\
\text { scale factor }\end{array}$ & Trapezoid $(0.5,1.26,1.82,2,2,3)$ \\
\hline Dry_Dep_Acc & Aer & Accumulation mode dry-deposition velocity scale factor & Trapezoid $(0.1,0.32,3.16,10,2,2)$ \\
\hline Dry_Dep_SO2 & Aer & $\mathrm{SO}_{2}$ dry-deposition velocity scale factor & Trapezoid $(0.2,0.56,1.78,5,2,2)$ \\
\hline Kappa_OC & Aer & Köhler coefficient of organic carbon & Trapezoid $(0.1,0.14,0.25,0.6,4,4)$ \\
\hline Sig_W & Aer & Updraft vertical velocity standard deviation & Trapezoid $(0.1,0.36,0.44,0.7,2,2)$ \\
\hline Dust & Aer & Dust emission scale factor & Trapezoid $(0.5,0.7,1.4,2,2,2)$ \\
\hline Rain_Frac & Aer & $\begin{array}{l}\text { Fraction of cloud-covered area in large-scale clouds } \\
\text { where scavenging occurs }\end{array}$ & Trapezoid $(0.3,0.31,0.55,0.7,2,3)$ \\
\hline Cloud_Ice_Thresh & Aer & $\begin{array}{l}\text { Threshold of cloud ice fraction above which nucleation } \\
\text { scavenging is suppressed }\end{array}$ & Trapezoid $(0.1,0.105,0.35,0.5,2,3)$ \\
\hline BC_RI & Aer & Imaginary part of the black carbon refractive index & Trapezoid $(0.2,0.352,0.616,0.8,4,2)$ \\
\hline OC_RI & Aer & Imaginary part of the organic carbon refractive index & Trapezoid $(0,0,0.05,0.1,2,6)$ \\
\hline
\end{tabular}

spond to changes in the cloud radiative fluxes and can induce changes in precipitation rates and cloud amount. The effect of perturbing Rad_Mcica_Sigma on reflected radiation is largest in regions of persistent stratocumulus cloud where low-altitude, high-albedo clouds occupy a substantial fraction of each model grid box.

\section{C_R_Correl}

Cloud and rain sub-grid horizontal correlation. The collocation of clouds and rain within the model is important because it determines the accretion rate of cloud droplets and aerosols by raindrops. Higher values cause more accretion because regions of high cloud water are closely correlated with regions of high precipitation. Perturbations to this pa- rameter affect cloud radiative properties by altering in-cloud interstitial aerosol concentrations and cloud amount.

\section{Niter BS}

Number of microphysics iteration sub-steps. The microphysical processing of in-cloud interstitial aerosols and cloud droplets is controlled by the cloud microphysics scheme within the physical atmosphere model. The values of this parameter determine the degree of processing within a model time step. Each iteration of the microphysics scheme allows drops to grow larger before precipitation occurs. Therefore, higher parameter values allow for greater microphysical processing and cause the model to produce less light rain. This affects the amount of liquid water within clouds and alters 
the amount of cloud, which is important for cloud radiative effects.

\section{Ent_Fac_Dp}

Entrainment amplitude scale factor. This convection scheme parameter controls the shape of the convective mass flux and the sensitivity of convection to relative humidity. Higher values reduce the depth of convection and suppress convective precipitation. This parameter is important for cloud radiative effects for several reasons. First, the retention of cloud water increases cloud amount and short-wave reflectivity. Second, lower-altitude clouds have a higher cloud top temperature and attenuate less of the long-wave energy emitted by the Earth's surface. Third, if atmospheric moisture is not precipitated convectively, the increase in relative humidity causes more large-scale frontal precipitation, which affects spatial distributions of aerosols and clouds and hence the aerosol ERF.

\section{Amdet_Fac}

Mixing detrainment rate scale factor. This parameter controls the rate of humidification of the atmosphere and the shape of the convective heating profile. Amdet_Fac is important for cloud radiative effects for similar reasons to Ent_Fac_Dp. Both parameters affect clouds through their influence on convection but through different mechanisms. Higher values of Amdet_Fac increase atmospheric humidity and temperature, leading to enhanced convection.

\section{Dbsdtbs_Turb_0}

The cloud erosion rate. This parameter alters the radiative properties of clouds by altering the rate at which unresolved sub-grid motions mix clear and cloudy air. Higher values cause more rapid mixing of clear, dry air into clouds, thereby reducing cloud liquid water content, autoconversion of cloud droplets to raindrops and cloud amount. The atmospheric lifetimes of aerosols and precursor gases are noticeably affected by this parameter.

\section{Mparwtr}

Maximum value of the function controlling convective parcel maximum condensate. Convective parcels near the Earth's surface precipitate when the amount of moisture reaches the threshold set by this parameter. Higher values increase cloud amount and lifetime by reducing convective precipitation. As with other convective parameters Mparwtr affects cloud radiative effects and aerosols by altering the spatial distributions of clouds and precipitation.

\section{Dec_Thres_Cld}

The threshold for cloudy boundary layer decoupling. Boundary layer stability plays an important role in determining the magnitude of cloud radiative effects because a wellmixed, stable boundary layer retains more heat and permits more dynamic activity. This parameter is the threshold at which the boundary layer decouples from the rest of the atmosphere. Hence, higher parameter values lead to a bettermixed boundary layer, increased cloudiness and longer incloud processing times for aerosols.

\section{Fac_Qsat}

Rate of change of convective parcel maximum condensate with altitude. The maximum amount of moisture a convective parcel can hold transitions from the threshold set by the parameter Mparwtr at the surface to a much smaller threshold at high altitudes. Fac_Qsat controls the rate at which this threshold changes with altitude. Fac_Qsat therefore influences cloud radiative effects through similar mechanisms to Mparwtr (higher values suppress precipitation and increase cloud amount and lifetime) but is more important in the upper boundary layer.

\subsubsection{Definition of the aerosol parameters}

Ageing

Ageing of hydrophobic aerosols. Carbonaceous aerosols are assumed to be non-hygroscopic when emitted into the atmosphere and cannot act as cloud condensation nuclei until sufficient layers of sulfuric acid and condensible organic matter coat their surface. This parameter is the number of monolayers of soluble material required to convert initially insoluble aerosols into cloud condensation nuclei. Higher values reduce the conversion rate of hydrophobic to hygroscopic aerosols. This parameter is important for aerosol ERF because it affects cloud condensation nuclei and the removal rate of highly absorbing carbonaceous aerosols from the atmosphere.

\section{Cloud_pH}

The pH of cloud droplets. The $\mathrm{pH}$ of cloud droplets is used in the aqueous chemistry module of GLOMAP to calculate the conversion of $\mathrm{SO}_{2}$ into sulfate particles. Cloud droplet $\mathrm{pH}$ depends on kinetic and thermodynamic processes that are not explicitly simulated. Therefore, we use a globally defined value of cloud droplet $\mathrm{pH}$ to control the reaction rate. Uncertainty in this parameter accounts for the simplification in its application. Higher values of this parameter increase sulfate production near $\mathrm{SO}_{2}$ emission sites and tend to reduce aerosol concentrations in remote regions (through effects on new particle formation). Therefore, the cloud $\mathrm{pH}$ parameter affects the spatial distribution of aerosols, which is important for aerosol ERF. 


\section{Carb_BB_Ems}

Carbonaceous biomass burning emission scale factor. Higher values of this scale factor increase the amount of carbonaceous aerosols emitted into the atmosphere from largescale biomass burning. Carbonaceous aerosols are important for aerosol ERF because they absorb solar radiation, and the resulting energy redistribution affects boundary layer temperatures and stability and can affect cloud cover (Gnanadesikan et al., 2017).

\section{Carb_BB_Diam}

Carbonaceous biomass burning emission diameter ( $\mathrm{nm}$ ). This parameter determines the size of carbonaceous aerosols at the time of emission. Higher values cause fewer, larger carbonaceous aerosols to be emitted for a given value of Carb_BB_Ems. Therefore, the total carbonaceous aerosol particle number is reduced, leading to fewer cloud condensation nuclei and a change in aerosol optical properties.

\section{Sea_Spray}

Sea spray aerosol emission scale factor. Aerosol ERF is sensitive to emission fluxes of natural aerosols because they strongly influence the pre-industrial background aerosol concentration and the relative magnitude of the change in aerosols over the industrial period. Perturbations to the winddriven emission fluxes affect aerosol distributions in marine and coastal regions.

\section{Anth_SO2}

Anthropogenic $\mathrm{SO}_{2}$ emission scale factor. $\mathrm{SO}_{2}$ gas forms $\mathrm{H}_{2} \mathrm{SO}_{4}$ molecules, which condense to form sulfate particles. Furthermore, $\mathrm{SO}_{2}$ condenses onto existing particles, increasing their size and solubility. Therefore, scaling anthropogenic $\mathrm{SO}_{2}$ emissions affects aerosol ERF by influencing the concentrations and composition of present-day aerosols.

\section{Volc_SO2}

Volcanic $\mathrm{SO}_{2}$ emission scale factor. Volcanic $\mathrm{SO}_{2}$ emissions are treated identically to anthropogenic $\mathrm{SO}_{2}$ emissions. However, they are present in both the pre-industrial and presentday atmospheres and so exert an influence on aerosol ERF through a similar mechanism to Sea_Spray by altering the pre-industrial aerosol concentration.

\section{BVOC_SOA}

Biogenic secondary aerosol formation from volatile organic compound scale factor. Secondary organic aerosols form through multi-stage oxidation reactions of biogenic volatile organic compounds (monoterpenes in this case). This parameter scales the secondary organic aerosol emission flux, with higher values producing larger emissions. Perturbing this parameter changes the aerosol concentration and size distribution in the pre-industrial and present-day atmosphere.

\section{DMS}

Dimethylsulfide surface ocean concentration scale factor. Perturbing the concentration of DMS in the oceans alters the wind-driven flux of DMS into the atmosphere. DMS is important for aerosol ERF because it is a source of natural aerosols which affect the pre-industrial aerosol background concentrations. Similar to the Sea_Spray parameter, DMS affects aerosol concentrations in marine and coastal regions. However, marine DMS concentrations increase with ocean temperature, so perturbations to this parameter will have the greatest influence on aerosol ERF in warmer months.

\section{Dry_Dep_Acc}

Accumulation mode dry-deposition velocity scale factor. Aerosols are removed from the atmosphere at a velocity calculated using Brownian diffusion, impaction and interception. This calculation in the GLOMAP model depends on wind speeds and surface roughness. High values of this parameter more readily remove accumulation mode aerosols from the atmosphere, causing a reduction in cloud condensation nuclei concentrations.

\section{Dry_Dep_SO2}

$\mathrm{SO}_{2}$ dry-deposition velocity scale factor. This parameter determines the removal of $\mathrm{SO}_{2}$ gas from air masses that interact with the surface. The removal of $\mathrm{SO}_{2}$ is important for aerosol ERF because $\mathrm{SO}_{2}$ is a precursor for sulfate particles and condenses onto existing particles, causing them to grow to the larger sizes needed to act as cloud condensation nuclei. Higher values of this parameter increase the removal rate of $\mathrm{SO}_{2}$ from the atmosphere. This affects aerosol size distributions by simultaneously reducing particle formation rates and the growth rates of existing aerosols.

\section{Kappa_OC}

Köhler coefficient of organic carbon. Aerosol water uptake efficiency is determined by "Köhler theory" using sizeand composition-dependent hygroscopicity factors $(\kappa$; Petters and Kreidenweis, 2007). Higher values of this parameter increase the water uptake efficiency of the organic material in the particles. Perturbations to this parameter will change the light-scattering efficiency of the particles and the droplet activation process, thereby affecting cloud microphysical processes. In particular, cloud-active aerosol concentrations in the pre-industrial atmosphere are expected to be susceptible to this parameter value (Liu and Wang, 2010). 


\section{Sig_W}

Updraft vertical velocity standard deviation. This parameter controls the width of the probability distribution of sub-grid vertical velocities used to calculate the activation of aerosols into cloud droplets. Higher Sig_W values widen the distribution of updraft velocities. The largest sub-grid updrafts within the distribution have the greatest influence on cloud droplet concentrations because, for any given supersaturation, a larger updraft velocity will cause a greater proportion of relatively small aerosols to activate. Higher values of Sig_W therefore increase cloud droplet concentrations and decrease precipitation efficiency (through reduced autoconversion rates), cloud liquid water content and cloud albedo. Sig_W perturbations have the greatest influence on cloud droplet concentrations in regions of relatively high aerosol concentrations because in such environments droplet activation is updraft-limited rather than aerosol-limited.

\section{Dust}

Dust emission scale factor. Dust aerosols are large, insoluble particles when emitted but are treated as hygroscopic once sufficiently aged by the condensation of soluble material onto the particle surface (as defined by the "ageing" parameter). We perturb dust emissions in our ensemble because they are important for the ERF $\mathrm{ARI}_{\text {AR }}$ component of aerosol ERF. Furthermore, dust influences cloud-active aerosol concentrations (Manktelow et al., 2010) and cloud droplet concentrations (Karydis et al., 2017).

\section{Rain_Frac}

Fraction of cloud-covered area in large-scale clouds where scavenging occurs. Rain and clouds do not correlate perfectly (as discussed in the C_R_Correl definition). Higher values of this parameter allow aerosols to be scavenged by raindrops over a greater fraction of cloudy areas. The value of this parameter is important for aerosol ERF because it affects aerosol atmospheric lifetimes.

\section{Cloud_Ice_Thresh}

Threshold of cloud ice fraction above which nucleation scavenging of aerosol material is suppressed. The scavenging of aerosol material in dynamic rain systems is controlled partly by the rain formation process - either the collisioncoalescence process, which efficiently removes many aerosol particles in raindrops, or the Wegener-Bergeron-Findeisen process in mixed-phase clouds, which leads to less aerosol scavenging and seems to account for the efficient wintertime transport of aerosols to the Arctic (Barrett et al., 2011; Browse et al., 2012). In our previous studies (Regayre et al., 2014, 2015) we defined a temperature below which scavenging was suppressed. Here, we instead use the mass fraction of ice to define a threshold above which no nucleation scaveng- ing occurs. Higher values require a greater proportion of ice to be present before scavenging is suppressed. This parameter is important for high latitude aerosol concentrations and cloud radiative effects (Browse et al., 2012; Regayre et al., 2015; Yoshioka et al., 2018).

\section{BC_RI}

Imaginary part of the black carbon refractive index. This parameter controls the absorption of radiation as it passes through aerosols containing black carbon. Higher values of the imaginary refractive index cause more energy to be absorbed and re-emitted by black carbon aerosols. The real part of the refractive index is defined according to the imaginary part, meaning that this parameter also controls the scattering of radiation by black carbon aerosols. Higher values of the real part cause more incoming radiation to be refracted towards the Earth's surface (more forward scattering). Perturbations to BC_RI affect ERF $_{\text {ARI }}$ as well as the vertical profile of atmospheric heating and hence convection, cloud amount and cloud radiative effects. Our simulations do not account for the effect of depositing light-absorbing carbonaceous aerosols on snow (Bond et al., 2013), nor the air-sea interactions that enhance rapid adjustments in marine regions (Gnanadesikan et al., 2017).

\section{OC_RI}

Imaginary part of the organic carbon refractive index. The absorption of radiation by organic carbon is controlled by this parameter. Unlike BC_RI, the real part of the organic carbon refractive index is held constant. Therefore, perturbations to this parameter have no effect on the refractive properties of organic carbon. Otherwise, OC_RI affects the atmosphere through the same mechanisms as BC_RI.

One potentially important parameter that we did not perturb is the autoconversion rate of cloud droplets into raindrops (although we did perturb Rain_Frac and C_R_Correl, which affect aerosol and cloud droplet removal by raindrops). The coupling between the GLOMAP model and the cloud microphysics scheme is currently one-way: cloud droplet concentrations calculated in GLOMAP are used in the autoconversion scheme and thereby affect precipitation rates, cloud liquid water content and albedo. However, precipitation only alters the cloud droplet concentrations in HadGEM and not aerosol concentrations within the GLOMAP model. For aerosol concentrations to be directly altered by the autoconversion process, the coupling would need to be two-way so that cloud droplet concentrations in GLOMAP would be consistent with those calculated in the atmospheric model's microphysics scheme.

Other HadGEM simulations have shown that over multiple cloud regimes the cloud liquid water path is not substantially affected by aerosols through autoconversion (Malavelle et al., 2017), suggesting that neglecting the uncertainty in this 
process is not important to our results. However, in relatively polluted regions (such as the North Atlantic) cloud liquid water path responses to aerosols in low-altitude clouds (particularly stratocumulus) are likely to be overestimated in the model because of known structural errors (Toll et al., 2017). The cloud liquid water path response to aerosols in low, warm clouds is weaker in HadGEM than in other global climate models (Ghan et al., 2016). Therefore, autoconversion may seem more important in other models but will likely be overstated (Toll et al., 2017). This process should be considered in future uncertainty analysis studies once shared model structural errors are addressed and the process uncertainty is better quantified.

\subsection{Statistical methodology}

Maximin Latin hypercube sampling was used to create a parameter combination design of 162 points with excellent space-filling properties that provide information on model output across the 27-dimensional parameter uncertainty space. A simulation with all parameters set to their median values (from distributions described in Table 1) was also included in the ensemble. Emulators were then constructed which describe individual model outputs (ToA flux, aerosol ERF and its components) over the 27-dimensional space of the uncertain parameters. Emulators provide a statistical representation of model output for all points within the multi-dimensional parameter space and have been widely used to analyse climate models (Lee et al., 2013; Carslaw et al., 2013; Tett et al., 2013; Regayre et al., 2014; Hamilton et al., 2014; Regayre et al., 2015; Johnson et al., 2015; Lee et al., 2016) as well as complex models in many other areas of science, including hydrology (Liu and Gupta, 2007), galaxy formation (Rodrigues et al., 2017) and disease transmission (Andrianakis et al., 2017).

In total 217 perturbed parameter simulations were created for each anthropogenic emission period including a set of 54 simulations with parameter combinations that augment the original design and were used to validate the emulators. Twenty-six simulations did not complete an annual cycle in at least one of the anthropogenic emission periods (1850, 1978 and 2008) because the combinations of parameters caused the model to fail. Hence, the ensemble of simulations for each period was made up of the remaining 191 simulations. Once emulators were validated, by ensuring that at least $75 \%$ of the validation simulations produced output within the relatively small emulator uncertainty bounds, new emulators conditioned on output from the 191 perturbed parameter simulations (with better space-filling properties) were created by combining the validation simulations with the original set of simulations.

Probability density functions (pdfs, Table 1) were used to represent expert beliefs about parameter uncertainty. We predominantly used trapezoidal distributions (Hetzel, 2012) to represent parameter uncertainty in order to avoid having an overly centralised multi-variate sample (Yoshioka et al., 2018).

By combining perturbed parameter ensembles with model emulation and then densely sampling emulator output using the extended-Fourier amplitude sensitivity test (FAST) sampling method (Saltelli et al., 1999), we were able to perform sensitivity analyses (Saltelli et al., 1999, 2000; Lee et al., 2012) and decompose the variance in model output into individual components. We used the percentage reduction in variance which would be achieved if a parameter value were known exactly as our main statistic for identifying the causes of uncertainty. Emulation and sensitivity analyses were applied at the individual model grid box level (degraded to N48 model resolution) as well as at the regional and global mean level for the ToA flux as well as the forcing terms. For the sensitivity analyses, samples of 270000 members were drawn from the emulators at parameter combinations determined by the parameter pdfs. The sensitivity analysis results are therefore informed by expert knowledge about the model behaviour in relation to the uncertain processes. However, for the constraint of aerosol ERF using ToA flux observations we sampled 1 million model variants using uniform pdfs. This sampling approach uses the expert-elicited parameter pdfs to determine the ranges of uniform pdfs for sampling but neglects expert prior beliefs about parameter value likelihoods. As such, the effects of applying the observational constraint and expert knowledge can be quantified and compared. Furthermore, the effect of applying the observational constraint on the uncertain parameter space can be more readily assessed when uniform pdfs are used to create the original sample because parameter combinations are more evenly spaced throughout the 27-dimensional parameter space.

Preliminary parameter combination screening tests revealed that values of Ent_Fac_Dp higher than around 1.8 in combination with values of Amdet_Fac higher than around 8.0 caused model simulations to fail. This part of the 27dimensional parameter space (a corner of a 2-D plane) was removed from the ensemble design and analyses. The sampling method used to perform the sensitivity analyses was adapted to reject samples from the 2-D corner of parameter space not included in the design. Rejected combinations of the Ent_Fac_Dp and Amdet_Fac parameters were re-sampled from the restricted 2-D parameter space without affecting the sampling frequency across the remaining 25dimensional parameter space.

\section{Results}

\subsection{Uncertainty in aerosol ERF and its components}

Figure 1 shows pdfs of the global mean aerosol ERF (from 1850 to 2008) and its components: $\mathrm{ERF}_{\mathrm{ARI}}$ and $\mathrm{ERF}_{\mathrm{ACI}}$. The $95 \%$ credible interval of aerosol ERF used in the sensitivity analysis is -2.18 to $-0.71 \mathrm{~W} \mathrm{~m}^{-2}$. Most of the uncer- 
tainty in aerosol ERF comes from the $\mathrm{ERF}_{\mathrm{ACI}}$ component, which has a credible interval of -2.20 to $-0.61 \mathrm{~W} \mathrm{~m}^{-2}$ and captures much of the recognised uncertainty in this forcing term (Myhre et al., 2013; Shindell et al., 2013). We also account for above-cloud aerosols (Ghan, 2013) in our calculation of $\mathrm{ERF}_{\mathrm{ACI}}$ and $\mathrm{ERF}_{\mathrm{ARI}}$, which affects the balance between these two components of aerosol ERF (Yoshioka et al., 2018). This adjustment results in distributions of weaker $E F_{A R I}$ values and stronger $E_{\text {ACI }}$ values in our sample compared to Myhre et al. (2013). We discuss these effects further in Sect. 3.1.2.

The sample of aerosol ERFs in Fig. 1 has already been constrained by our choice of probability distributions for the uncertain parameters (Table 1). When we use uniform parameter distributions to sample parameter combinations (Sect. 2.3), the credible range (95\%) of aerosol ERFs is -2.65 to $-0.68 \mathrm{~W} \mathrm{~m}^{-2}$. When expert beliefs about parameter value likelihoods are applied, the aerosol ERF credible range is only -2.18 to $-0.71 \mathrm{~W} \mathrm{~m}^{-2}$ (Fig. 1a). This implies that by applying the combined knowledge of experts with an understanding of the model processes and parametrisations we have effectively reduced the aerosol ERF credible range by around $25 \%$.

The strongest aerosol ERFs in our distribution would lead to a negative forcing when combined with best estimates of changes in other forcing agents over the industrial period. A net negative forcing is incompatible with the observed increase in global mean surface temperatures over the industrial period (e.g. HadCRUT4, 2017). However, there is substantial uncertainty in the ERFs of multiple other forcing agents (Myhre et al., 2013; Fig. 8.16 and 8.18), so our most negative aerosol ERF values cannot be considered implausible using these criteria. Structural aspects of the model could account for the strongest forcings. For example, our model is missing marine sources of organic aerosols and related processes (Gantt et al., 2015) which, if included, would act as an important source of ice-nucleating particles (Vergara-Temprado et al., 2017) and pre-industrial aerosols (Gordon et al., 2017), which would weaken the aerosol forcing (Carslaw et al., 2013). However, our perturbed parameter ranges were to some extent intended to encompass the uncertainty caused by those structural deficiencies we were aware of. The values in the tails of the aerosol ERF pdf are likely to be the result of setting multiple parameters important for aerosol ERF to extreme values, which are also likely to cause extreme present-day ToA flux values and be considered implausible when compared to observations (Sect. 3.5).

Figure 1 also shows the separate effects of the 18 combined aerosol parameters and the 9 combined physical atmosphere model uncertainties. Neglecting the uncertainty in aerosol parameters (by setting them to their median values in all model variants) results in a $95 \%$ credible aerosol ERF interval of -1.98 to $-1.04 \mathrm{~W} \mathrm{~m}^{-2}$, whilst neglecting uncertainty in atmospheric parameters results in a credible interval of -2.00 to $-0.90 \mathrm{~W} \mathrm{~m}^{-2}$. Summary statistics of forcing
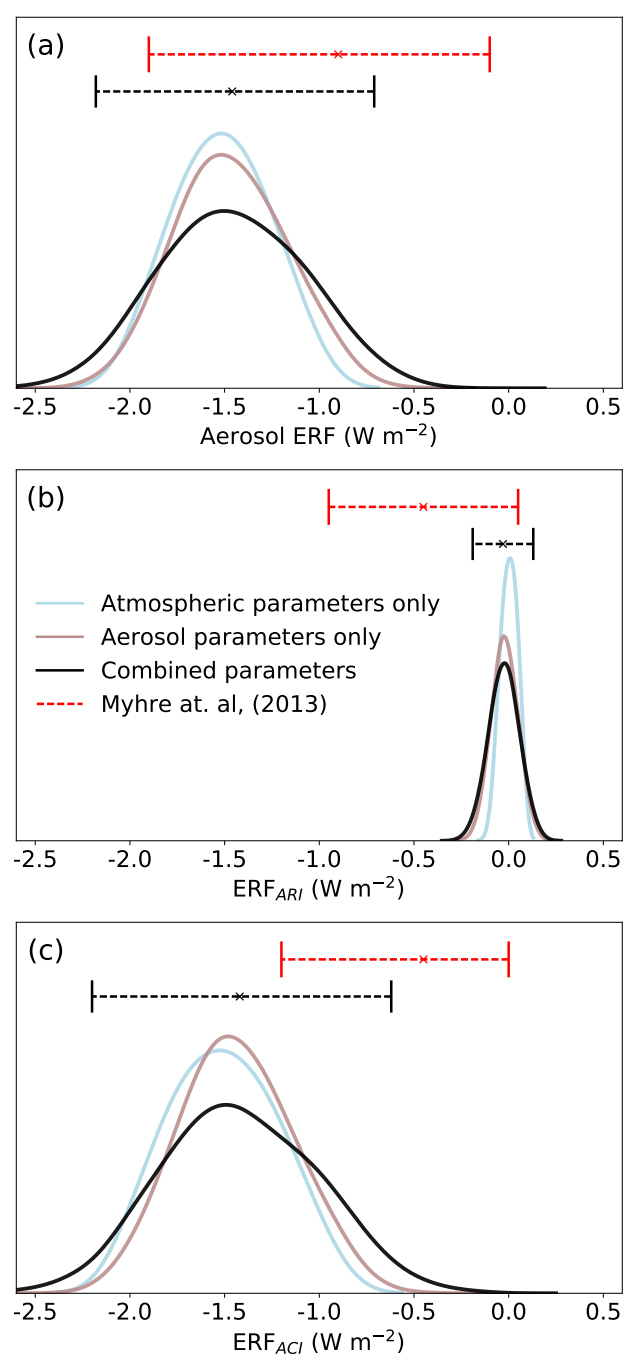

Figure 1. Probability density functions of 1850-2008 (a) aerosol ERF, (b) $\mathrm{ERF}_{\mathrm{ARI}}$ and (c) $\mathrm{ERF}_{\mathrm{ACI}}$. Each sample contains 270000 emulator-derived model variants informed by the expert-elicited prior probability distributions of parameter values. Samples with aerosol and atmospheric parameter uncertainties neglected (Table 1) were obtained by setting each neglected parameter to its median value in the corresponding pdf. Ninety-percent credible intervals from Myhre et al. (2013) are presented as red horizontal lines, with best estimates marked using crosses. Our $95 \%$ credible intervals are presented in black, and the sample median is presented using a cross.

from these samples are presented in Table 2. The distribution of aerosol ERF (as well as $\mathrm{ERF}_{\mathrm{ARI}}$ and $\mathrm{ERF}_{\mathrm{ACI}}$ ) is wider and flatter (has a larger variance) in the combined sample than the distributions of atmosphere-only and aerosol-only sampled values. This suggests that important interactions between atmospheric and aerosol parameters cause the most extreme aerosol ERF values. The effects of the aerosol and physical model uncertainties do not have an additive effect on the aerosol ERF uncertainty because of compensating ef- 
Table 2. Summary statistics for the pdfs of 1850-2008 aerosol ERF, ERF ARI and ERF ACI presented in Fig. 1. Perturbations to atmospheric and/or aerosol parameters cause the uncertainty in model output in each case. All values are in watts per metre $\left(\mathrm{W} \mathrm{m}^{-2}\right)$. For all samples the null hypotheses of equivalent means or standard deviations are rejected at the $99 \%$ confidence level using Welch's $t$ (Welch, 1947) and Bartlett (Snedecor and Cochran, 1989) tests respectively.

\begin{tabular}{llcccc}
\hline Sample & Perturbations & Mean & $\begin{array}{c}\text { Standard } \\
\text { deviation }\end{array}$ & $\begin{array}{c}95 \% \text { credible } \\
\text { interval }\end{array}$ & $\begin{array}{c}\text { Credible } \\
\text { range }\end{array}$ \\
\hline ERF & Atmosphere and aerosol & -1.46 & 0.38 & $(-2.18,-0.71)$ & 1.46 \\
& Atmosphere only & -1.51 & 0.25 & $(-1.98,-1.04)$ & 0.94 \\
& Aerosol only & -1.47 & 0.29 & $(-2.01,-0.90)$ & 1.11 \\
\hline \multirow{2}{*}{ RRF $_{\text {ARI }}$} & Atmosphere and aerosol & -0.03 & 0.08 & $(-0.19,0.13)$ & 0.31 \\
& Atmosphere only & 0.00 & 0.04 & $(-0.08,0.08)$ & 0.16 \\
& Aerosol only & -0.02 & 0.07 & $(-0.16,0.11)$ & 0.27 \\
\hline \multirow{2}{*}{ RRF $_{\text {ACI }}$} & Atmosphere and aerosol & -1.42 & 0.41 & $(-2.20,-0.61)$ & 1.59 \\
& Atmosphere only & -1.51 & 0.29 & $(-2.04,-0.96)$ & 1.08 \\
& Aerosol only & -1.43 & 0.30 & $(-1.99,-0.85)$ & 1.14 \\
\hline
\end{tabular}

fects between the groups of parameters. These results show that both atmospheric and aerosol parameter perturbations are required to comprehensively sample model uncertainty. The main atmospheric and aerosol sources of aerosol ERF uncertainty are identified in Sect. 3.2.1.

\subsubsection{Uncertainty in $\mathbf{E R F}_{\mathrm{ACI}}$}

Maps of the means and standard deviations of $\mathrm{ERF}_{\mathrm{ACI}}$ resulting from perturbations to our 27 atmospheric and aerosol parameters are presented in Fig. 2. Forcings stronger than $-3.5 \mathrm{~W} \mathrm{~m}^{-2}$ are concentrated over anthropogenic aerosol sources (particularly Asia, America and Europe) and in marine stratocumulus regions (Atlantic Ocean, North Pacific Ocean and the South Pacific Ocean off the South American coast). The standard deviation of $\mathrm{ERF}_{\mathrm{ACI}}$ is largest (up to $6 \mathrm{~W} \mathrm{~m}^{-2}$ ) in the same regions and is typically of the same order of magnitude as the mean regional value. The spatial distribution of mean $\mathrm{ERF}_{\mathrm{ACI}}$ is very similar to the Atmospheric Chemistry and Climate Model Intercomparison Project (ACCMIP) multi-model mean pattern (Shindell et al., 2013). However, the magnitudes of forcing differ, particularly over remote marine regions. For example, our mean $E F_{A C I}$ is stronger than $-5 \mathrm{~W} \mathrm{~m}^{2}$ over much of the North Pacific Ocean, whereas the ACCMIP mean aerosol ERF in the Pacific is stronger than $-3.5 \mathrm{~W} \mathrm{~m}^{2}$ only in coastal regions near to anthropogenic sources. These strong remote marine $\mathrm{ERF}_{\mathrm{ACI}}$ values go some way to explaining the differences in global mean $\mathrm{ERF}_{\mathrm{ACI}}$ between our sample (around $-1.4 \mathrm{~W} \mathrm{~m}^{2}$ ) and the ACCMIP multi-model mean (around $-0.9 \mathrm{~W} \mathrm{~m}^{2}$ ). In part, the magnitude of our ERF $\mathrm{ACI}$ values are caused by the above-cloud aerosol adjustment (Ghan, 2013). Our model has a relatively weak cloud liquid water path response to aerosols (Ghan et al., 2016; Malavelle et al., 2017), which suggests that our very negative marine forcing values are not caused by an overly strong aerosol second indirect effect.

\subsubsection{Uncertainty in $\mathbf{E R F}_{\mathrm{ARI}}$}

Figure 3 shows the spatial pattern of mean $E_{R F} F_{A R I}$ and its standard deviation. Global mean $\mathrm{ERF}_{\mathrm{ARI}}$ is near zero (95\% credible range: -0.19 to $0.13 \mathrm{~W} \mathrm{~m}^{-2}$; Fig. 1; Table 2). Although the possibility of a globally positive $\mathrm{ERF}_{\mathrm{ARI}}$ has previously been considered unlikely (Boucher et al., 2013), it has important implications for our understanding of interactions between absorbing aerosols, cloud processes and boundary-layer dynamics. The near-zero global mean $E F_{A R I}$ results from the cancellation of positive and negative regional forcings. Positive mean $\mathrm{ERF}_{\mathrm{ARI}}$ values (up to $10 \mathrm{~W} \mathrm{~m}^{-2}$ ) occur in regions where carbonaceous aerosols often overlie relatively high-albedo clouds (continental Asia and off the west coasts of Africa and South America). It is in these regions that the standard deviation of $\mathrm{ERF}_{\mathrm{ARI}}$ is also largest (up to $5 \mathrm{~W} \mathrm{~m}^{-2}$ ). Light-absorbing aerosols above cloud heat the local atmosphere, which can suppress convection and affect cloud cover. This is important for calculating the $\mathrm{ERF}_{\mathrm{ARI}}$ from our simulations because we account for above-cloud scattering and absorption of aerosols in line with Ghan (2013). Neglecting the effects of above-cloud aerosols in the $\mathrm{ERF}_{\mathrm{ARI}}$ produces no positive values for this forcing component ( $95 \%$ credible interval: -0.69 to -0.24 ; Yoshioka et al., 2018). Therefore, the magnitude of $\mathrm{ERF}_{\mathrm{ARI}}$ over Asia, Africa and South America (where it is positive and reduces cloud cover) determines the sign of global mean $\mathrm{ERF}_{\mathrm{ARI}}$. 

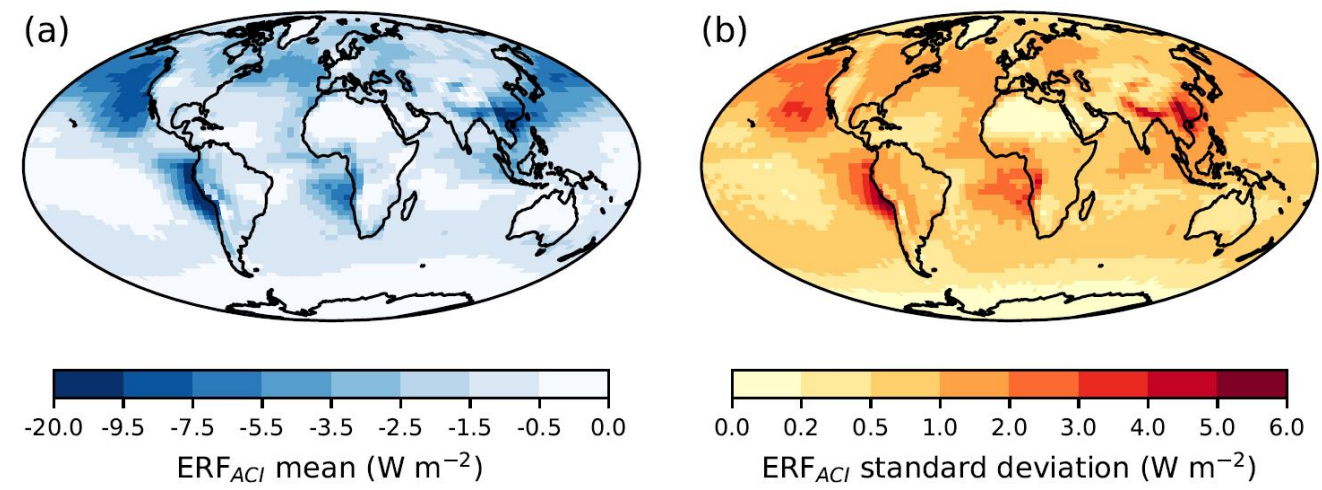

Figure 2. (a) Mean and (b) standard deviation for 1850-2008 ERF $\mathrm{ACI}_{\text {f }}$ forcing. Values were calculated using output from 270000 emulatorderived model variants at the individual pixel level once degraded to N48 model resolution. These samples of model variants are informed by the expert-elicited parameter pdfs.
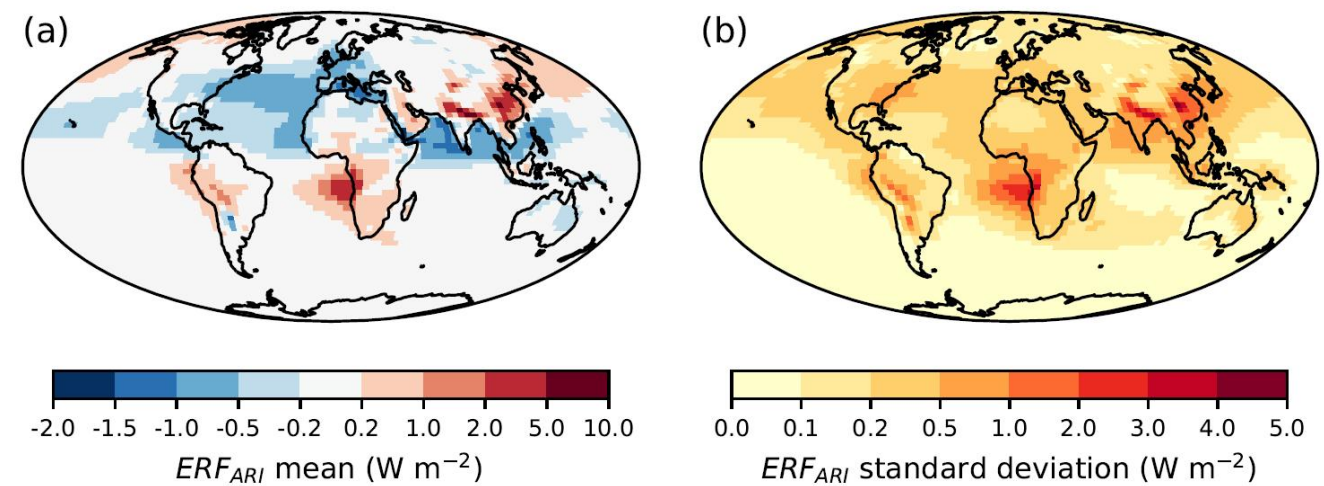

Figure 3. (a) Mean and (b) standard deviation of 1850-2008 ERF ARI forcing. Values were calculated using output from 270000 emulatorderived model variants at the individual pixel level. These samples of model variants are informed by the expert-elicited parameter pdfs.

\subsection{Sources of uncertainty in aerosol ERF and its components}

\subsubsection{Sources of uncertainty in global mean $\mathbf{E R F}_{\mathrm{ACI}}$}

Figure 4 summarises the causes of variance (sometimes referred to as the "main effects") in global mean $\mathrm{ERF}_{\mathrm{ACI}}$, $E_{\text {ERF }}$ ARI and aerosol ERF. Natural aerosol emissions (here, predominantly Sea_Spray, DMS and BB_Diam) persist as important sources of industrial-period $\mathrm{ERF}_{\mathrm{ACI}}$ uncertainty, as in previous studies of several climate models (Wilcox et al., 2015) and the aerosol-only component of a global model (Carslaw et al., 2013). Here, natural aerosols are responsible for around $63 \%$ of the proportion of $\mathrm{ERF}_{\mathrm{ACI}}$ variance caused by aerosol parameters, compared to $45 \%$ of the variance in aerosol-cloud-albedo effect forcing in the absence of rapid atmospheric adjustments (Carslaw et al., 2013). However, by far the largest source of uncertainty is the Rad_Mcica_Sigma parameter. This cloud radiation parameter affects the spatial homogeneity of simulated clouds, altering (amongst other things) reflected radiation, tropospheric temperature profiles and cloud amount (Sect. 3.3). Therefore, by altering the radiative state of clouds in the pre-industrial and present-day atmospheres, Rad_Mcica_Sigma affects uncertainty in the simulated change in cloud radiative state (the $\left.\mathrm{ERF}_{\mathrm{ACI}}\right)$. Model process parameters Sig_W and C_R_Correl cause uncertainty in $\mathrm{ERF}_{\mathrm{ACI}}$ by altering the efficiency of the cloud droplet activation and deposition processes respectively. Other parameters cause a small amount of the $\mathrm{ERF}_{\mathrm{ACI}}$ uncertainty but only in individual months. Therefore, the six parameters and associated processes identified here are the key to understanding the uncertainty in the global, annual mean $\mathrm{ERF}_{\mathrm{ACI}}$ in HadGEM.

\subsubsection{Sources of uncertainty in global mean $\mathbf{E R F}_{\mathrm{ARI}}$}

The sources of global mean $\mathrm{ERF}_{\mathrm{ARI}}$ variance are summarised in Fig. 4b. Parameters related to the emission and radiative properties of carbonaceous absorbing aerosols (BC_RI, OC_RI and BB_Ems) are amongst the largest sources of $\mathrm{ERF}_{\mathrm{ARI}}$ variance in all months. However, the emission flux of carbonaceous aerosols (BB_Ems) and the radiative prop- 

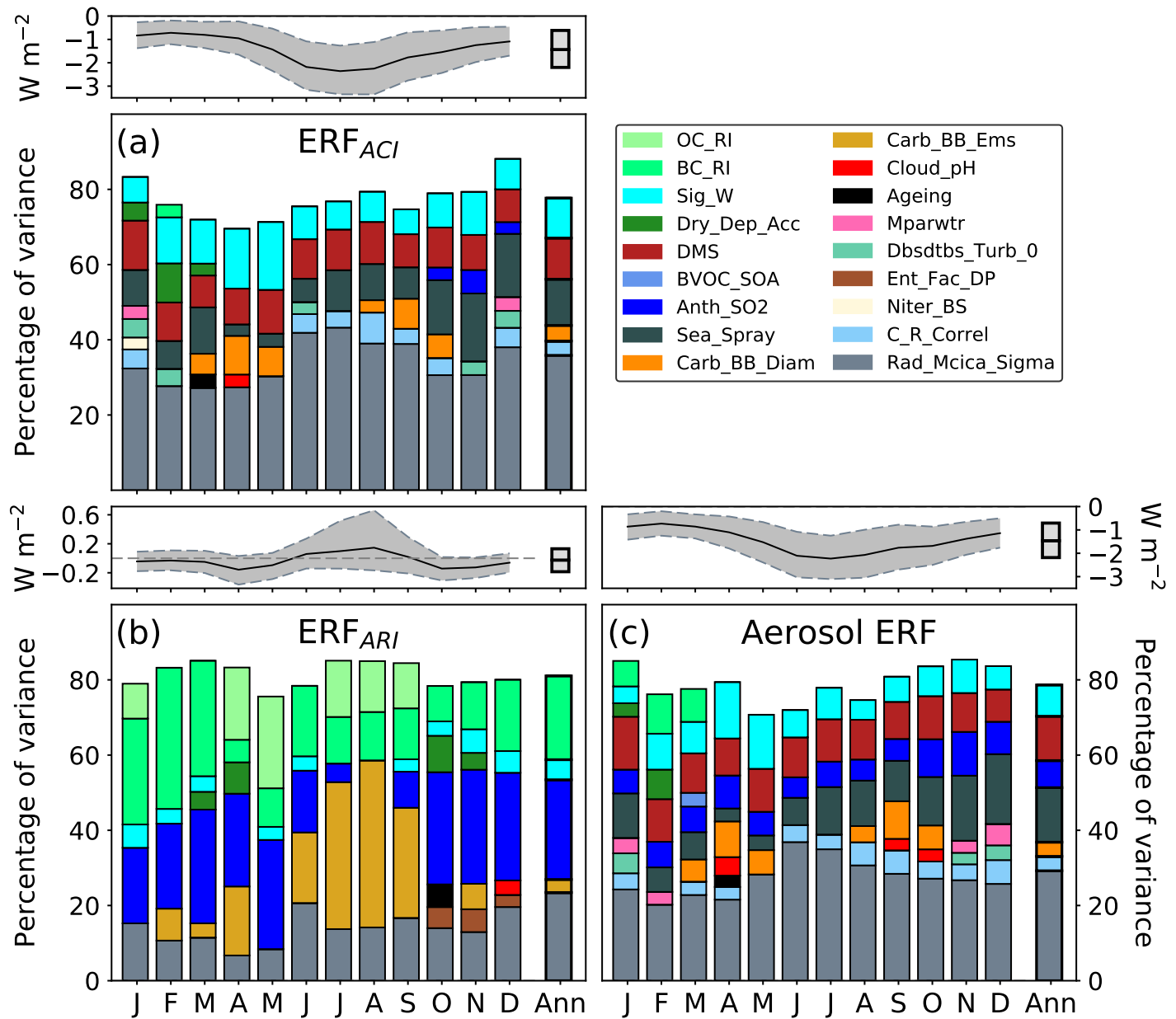

Figure 4. Percentage contributions to variance in global, monthly and annual mean 1850-2008 (a) $\mathrm{ERF}_{\mathrm{ACI}}$, (b) $\mathrm{ERF}_{\mathrm{ARI}}$ and (c) aerosol ERF. Each bar contains only those parameters that cause at least $3 \%$ of the variance, and interactions between parameters are neglected. Therefore, the percentage of variance accounted for is less than $100 \%$. The monthly and annual median values and $95 \%$ credible intervals (from the 270000 model variants) are displayed in the top panel. The monthly median values are connected in bold, and the credible intervals are shaded grey.

(a)
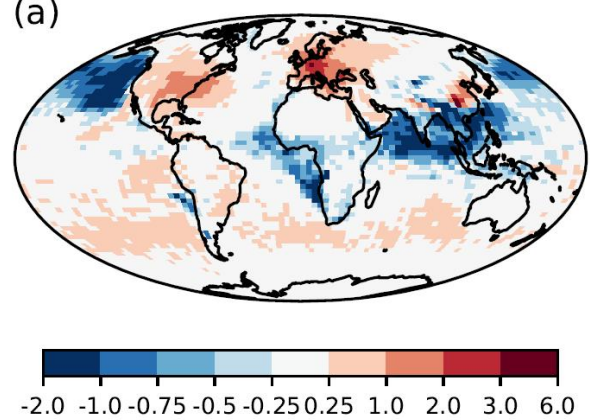

Aerosol ERF mean $\left(\mathrm{W} \mathrm{m}^{-2}\right)$ (b)
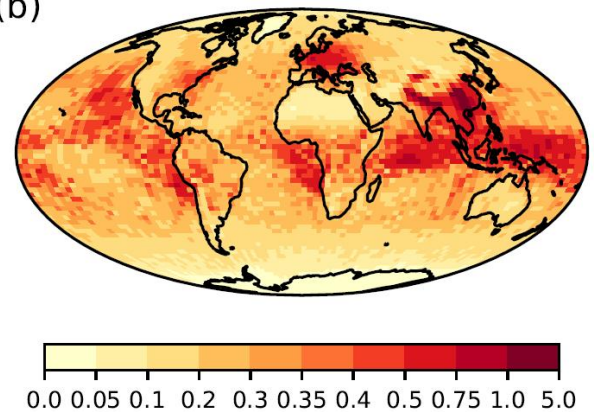

Aerosol ERF standard deviation $\left(\mathrm{W} \mathrm{m}^{-2}\right)$

Figure 5. (a) Mean and (b) standard deviation of 1978-2008 aerosol ERF. Values were calculated using output from 270000 emulatorderived model variants at the individual pixel level. These samples of model variants are informed by the expert-elicited parameter pdfs. 
erties of organic carbonaceous aerosols (OC_RI) cause much

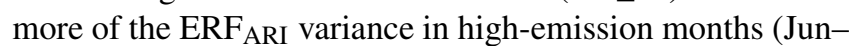
Aug) than they do in the annual mean. In other months with lower concentrations of carbonaceous aerosols, uncertainty in anthropogenic emissions (here, Anth_SO2) is the largest source of global mean $\mathrm{ERF}_{\mathrm{ARI}}$ variance. Anthropogenic emissions affect the $\mathrm{ERF}_{\mathrm{ARI}}$ by influencing aerosol properties in the present-day atmosphere. Other parameters (notably, Rad_Mcica_Sigma and Sig_W) affect the balance between $\mathrm{ERF}_{\mathrm{ACI}}$ and $\mathrm{ERF}_{\mathrm{ARI}}$ by altering cloud radiative properties which are important for calculating above-cloud aerosol effects (Ghan, 2013). Rad_Mcica_Sigma and Sig_W are the only parameters identified as important causes of uncertainty in both $\mathrm{ERF}_{\mathrm{ACI}}$ and $\mathrm{ERF}_{\mathrm{ARI}}$.

\subsubsection{Sources of uncertainty in industrial-period global mean aerosol ERF}

The aerosol ERF is the sum of the $\mathrm{ERF}_{\mathrm{ACI}}$ and $\mathrm{ERF}_{\mathrm{ARI}}$. Therefore, the sources of aerosol ERF variance are also sources of variance in the forcing components. The causes of aerosol ERF variance are summarised in Fig. 4c. Aerosol ERF shares more sources of variance with $E F_{A C I}$ than with $E F_{A R I}$ because $E F_{A C I}$ is the stronger and more uncertain forcing component (Fig. 1). Natural aerosol emissions (Sea_Spray, DMS and BB_Diam) and model process parameters (Sig_W and C_R_Correl) collectively cause over half of the aerosol ERF variance. Each of these key parameters causes a similar proportion of the aerosol ERF and $E F_{A C I}$ variances. However, the cloud radiation parameter (Rad_Mcica_Sigma) causes more of the $\mathrm{ERF}_{\mathrm{ACI}}$ variance (around $35 \%$ ) than aerosol ERF variance (less than 30\%), despite also causing around $25 \%$ of the $\mathrm{ERF}_{\mathrm{ARI}}$ variance. This suggests that the $\mathrm{ERF}_{\mathrm{ACI}}$ and $\mathrm{ERF}_{\mathrm{ARI}}$ responses to Rad_Mcica_Sigma are of opposite sign and thus partially cancel in the aerosol ERF calculation. The other main difference between sources of aerosol ERF and $\mathrm{ERF}_{\mathrm{ACI}}$ variance comes from anthropogenic emissions. Anthropogenic emission uncertainty (Anth_SO2) causes up to $10 \%$ of the aerosol ERF variance in all months. However, Anth_SO2 only causes a small percentage of the $\mathrm{ERF}_{\mathrm{ACI}}$ variance in a few months. Therefore, this parameter's contribution to aerosol ERF variance is predominantly through its influence on the $\mathrm{ERF}_{\mathrm{ARI}}$ component of forcing.

\subsubsection{Sources of uncertainty in multi-decadal aerosol ERF}

The causes of aerosol radiative forcing uncertainty are known to depend on the anthropogenic emission period examined (Carslaw et al., 2013; Regayre et al., 2014). A more detailed understanding of the causes of uncertainty in aerosol ERF requires sensitivity analyses over multiple time periods. In this section, we examine the pattern of uncertainty in multidecadal (1978-2008) aerosol ERF, identify the main causes of uncertainty in multi-decadal aerosol ERF and discuss how these results inform our understanding of aerosol ERF on longer timescales.

Figure 5 shows the spatial pattern of mean aerosol ERF and its standard deviation over the 1978-2008 period. Global anthropogenic sulfate emissions peaked in the late 1970s (Lamarque et al., 2010) and then decreased in Europe and North America as a result of clean-air legislation, but increased significantly in Asia (Smith et al., 2011). Therefore, there are distinct regions of positive and negative aerosol ERF in the 1978-2008 period. The cancellation of the regional aerosol ERFs of opposite sign causes a near-zero global mean aerosol ERF (95\% credible range of -0.6 to $0.8 \mathrm{~W} \mathrm{~m}^{-2}$ ). Over continental land masses, the aerosol ERF standard deviation is largest (between 0.5 and $5 \mathrm{~W} \mathrm{~m}^{-2}$ ) in regions of substantial mean aerosol ERF (absolute mean larger than around $1 \mathrm{~W} \mathrm{~m}^{-2}$ ). The aerosol ERF standard deviation is larger than around $0.3 \mathrm{~W} \mathrm{~m}^{-2}$ over most marine regions and is largest over regions of persistent stratocumulus cloud, even when the mean forcing is near-zero (e.g. off the west coast of South America). This suggests the sign of recent-decadal aerosol ERF forcing is uncertain over those regions.

The sources of variance in aerosol ERF and its components over the 1978-2008 period are summarised in Fig. 6. The sign of the aerosol ERF over the 1978-2008 period is uncertain for much of the year and is only definitively negative in the Northern Hemisphere summer. The cancellation of positive and negative regional aerosol ERFs has three main implications for the global mean sensitivity analysis. Firstly, not all of the causes of regional aerosol ERF will be evident in the global mean analysis (Regayre et al., 2015). Nevertheless, the causes of uncertainty in global mean 1978-2008 aerosol ERF will inform our understanding. Secondly, the causes of global mean aerosol ERF uncertainty are seasonally dependent because changes in the magnitude of incoming solar radiation determine the relative importance of regional uncertainties. Thirdly, the competing regional effects cause the total variance accounted for by individual parameters to be much less than $100 \%$ (as low as $55 \%$ in some months), with many parameters causing only a small amount (around $5 \%$ ) of the variance. This suggests that important interactions between multiple parameters in multiple regions have been causing much of the global mean aerosol ERF variance in recent decades.

There are multiple ways in which the causes of aerosol ERF uncertainty in the 1978-2008 period differ from those in the 1850-2008 period. Firstly, natural aerosol emission parameters have little influence on recent-decadal aerosol ERF uncertainty because the global mean 1978-2008 aerosol ERF depends more linearly on changing anthropogenic emissions than the 1850-2008 aerosol ERF (Carslaw et al., 2013). Secondly, the cloud radiation parameter Rad_Mcica_Sigma causes very little (less than 3\%) of the 1978-2008 aerosol ERF variance. The reduced importance of this parameter as 


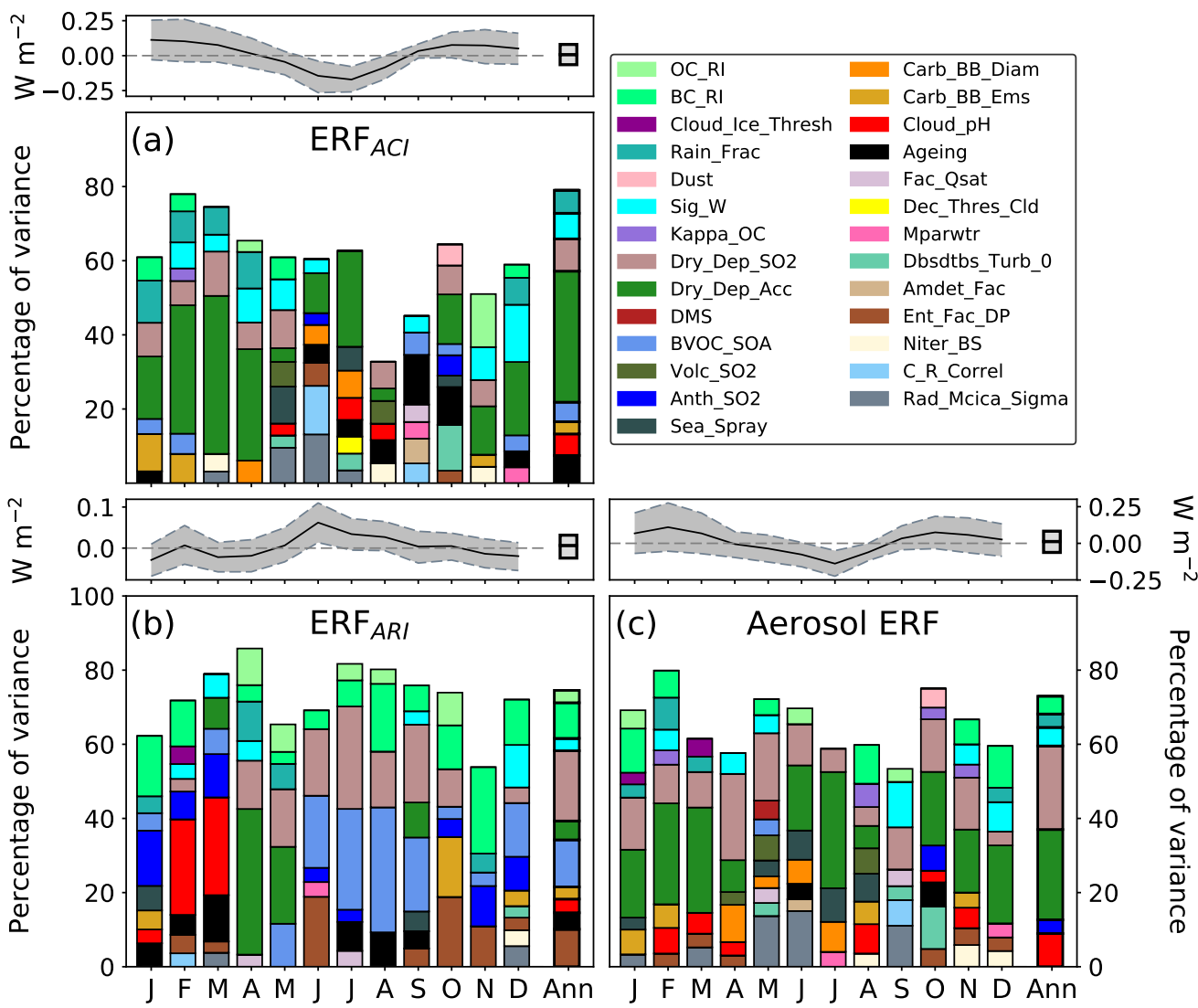

Figure 6. Percentage contributions to variance in 1978-2008 global, monthly and annual mean (a) ERF $\mathrm{ACI}$, (b) ERF $\mathrm{ARI}_{\text {and }}(\mathbf{c})$ aerosol ERF. Figure features are identical to Fig. 4.

a cause in aerosol ERF uncertainty results from the cancellation of regional aerosol ERFs of opposite sign, which also depends on the linearity of the multi-decadal aerosol ERF response to anthropogenic emission changes. Thirdly, in the 1978-2008 period anthropogenic and model process parameters are a larger source of aerosol forcing uncertainty, as in previous analysis of this period (Regayre et al., 2014). Here, uncertainty in the deposition rates of aerosols and aerosol precursor gases account for most (around $20 \%$ each) of the multi-decadal aerosol ERF variance. The aerosol process parameter Cloud_pH causes another 10\% of the 1978-2008 aerosol ERF variance. The anthropogenic emission parameter Anth_SO2 and other model process parameters (Sig_W, Rain_Frac and BC_RI) each cause only a small amount (around $3 \%$ ) of the variance.

\subsection{Sources of uncertainty in ToA radiative flux}

Identifying the sources of ToA reflected short-wave radiation (RSR) uncertainty will inform our understanding of how radiative flux measurements can help to constrain the aerosol ERF uncertainty (Lohmann and Ferrachat, 2010) because the aerosol ERF is essentially the aerosol-forced change in
RSR between the pre-industrial (or 1978) and present-day atmospheres (plus additional small changes in outgoing longwave radiation). The causes of present-day ToA RSR variance are summarised in Fig. 7 and are very similar in the pre-industrial and 1978 atmospheres (not shown).

The dominant source of ToA RSR uncertainty is the cloud radiation parameter Rad_Mcica_Sigma, which was also the dominant parameter for the pre-industrial to present-day aerosol ERF. Uncertainty in this parameter alone causes over $60 \%$ of the RSR variance by altering the total cloud albedo. The dominant role of this cloud radiative parameter in causing uncertainty in the ToA radiative flux and aerosol ERF suggests that constraining this parameter to a very narrow range should constrain the uncertainty in radiative fluxes (Haerter et al., 2009; Lohmann and Ferrachat, 2010) and consequentially in aerosol ERF (Lee et al., 2016). But of course, there are a number of other parameters (Dbsdtbs_Turb_0, Ent_Fac_DP, Sig_W and C_R_Correl) that cause ToA RSR uncertainty by altering the amount and/or albedo of clouds in the model. The mechanisms for altering cloudiness and therefore the ToA radiative flux are different for each parameter. The Dbsdtbs_Turb_0 parameter causes around 10\% of the ToA RSR variance by altering the mixing rate of clean 


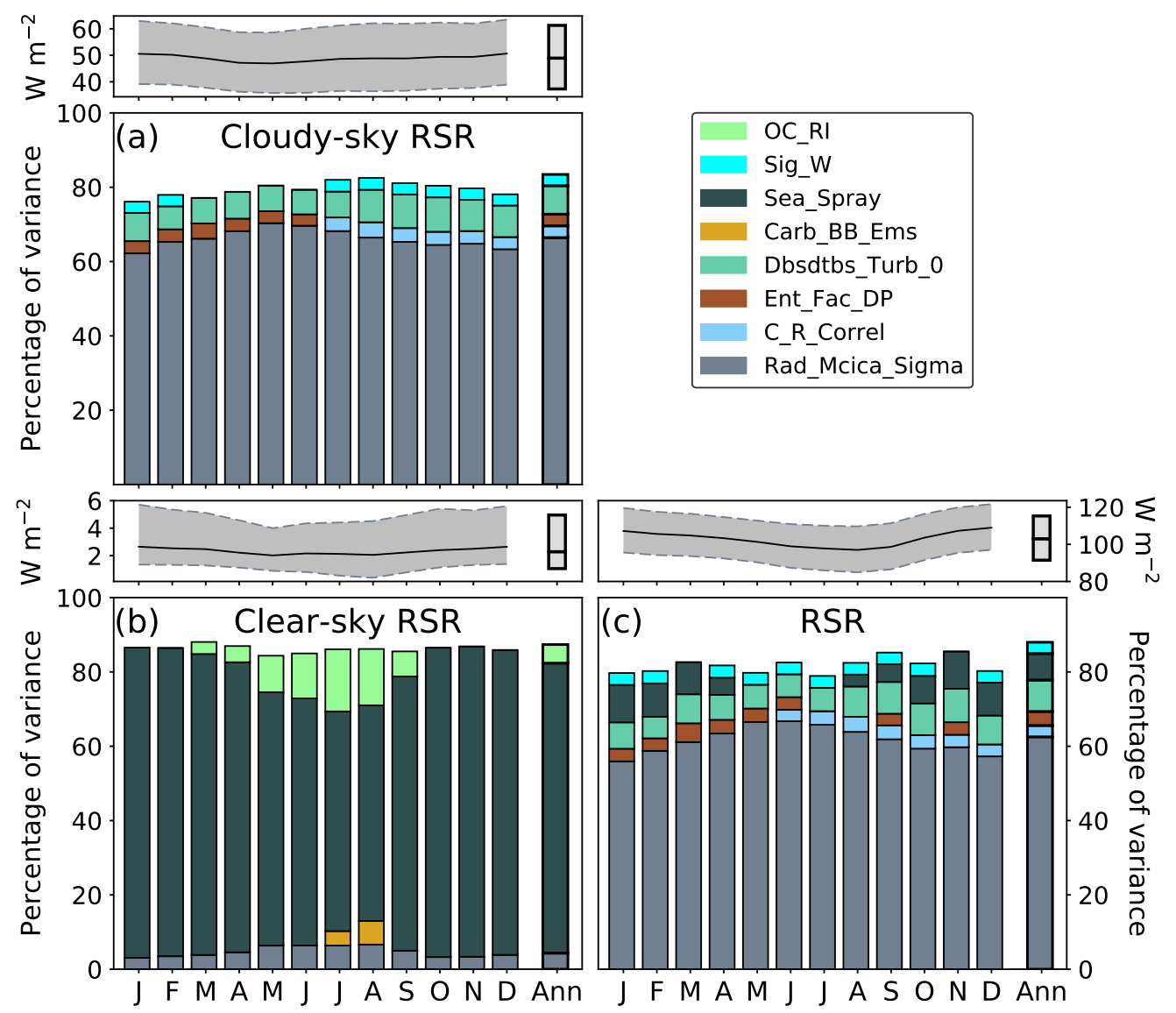

Figure 7. Percentage contributions to variance in present-day (2008) global, monthly and annual mean ToA (a) cloudy-sky RSR, (b) clear-sky RSR and (c) RSR. Figure features are identical to Fig. 4.

and cloudy air masses. Increasing the proportion of dry air in clouds has a dramatic effect on the amount of low-altitude cloud simulated in the model, making Dbsdtbs_Turb_0 the dominant cause of uncertainty in low-altitude cloud fraction (Fig. 8). The Ent_Fac_Dp, Sig_W and C_R_Correl parameters each cause around $5 \%$ of the RSR variance. The Ent_Fac_Dp parameter affects the strength of convection, which also alters precipitation rates and the vertical distribution of simulated clouds. Sig_W controls the activation of cloud condensation nuclei into cloud droplets (affecting droplet effective radius and cloud albedo), and C_R_Correl alters the rate of cloud droplet accretion by precipitating raindrops. The only parameter to cause ToA RSR variance (around $10 \%$ ) by directly altering atmospheric aerosol concentrations is Sea_Spray.

Figure 9 summarises the relative contributions of atmospheric and aerosol parameters to uncertainty in global mean values of present-day ToA RSR (from Fig. 7) and aerosol ERFs over the periods 1978-2008 (Fig. 6) and 1850-2008 (Fig. 4). Atmospheric parameters cause the majority (around $80 \%$ ) of the variance in present-day ToA radiative flux, but only around $30 \%$ of the variance in 1850-PD aerosol
ERF and less than $10 \%$ of the 1978-PD aerosol ERF variance. The rest of the uncertainty is attributable to the aerosol model. This disparity arises because contributions to variance in aerosol ERF depend on how parameters influence the atmosphere's response to the change in anthropogenic emissions, whilst RSR variance depends on how they influence the state of the atmosphere.

\subsection{Identifying the sources of uncertainty at the regional level}

\subsubsection{Regional sources of uncertainty}

Regional forcings can be important drivers of global and regional climate change (Chalmers et al., 2012; Booth et al., 2012; Bollasina et al., 2013; Shindell et al., 2013; Kirtman et al., 2013; Villarini and Vecchi, 2013; Allen et al., 2014). Furthermore, important sources of aerosol forcing uncertainty may be overlooked if regional sensitivity analysis results are neglected (Regayre et al., 2015). Examining how these sources of regional forcing uncertainty combine to cause uncertainty in global mean forcing uncer- 

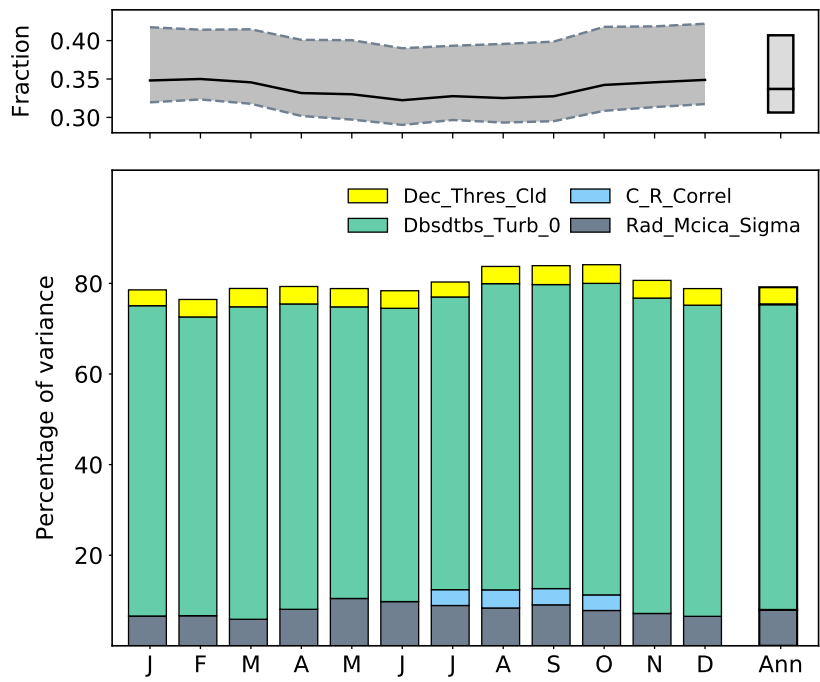

Figure 8. Percentage contributions to variance in presentday (2008) global, monthly and annual mean low-altitude cloud amount. Figure features are identical to Fig. 4.

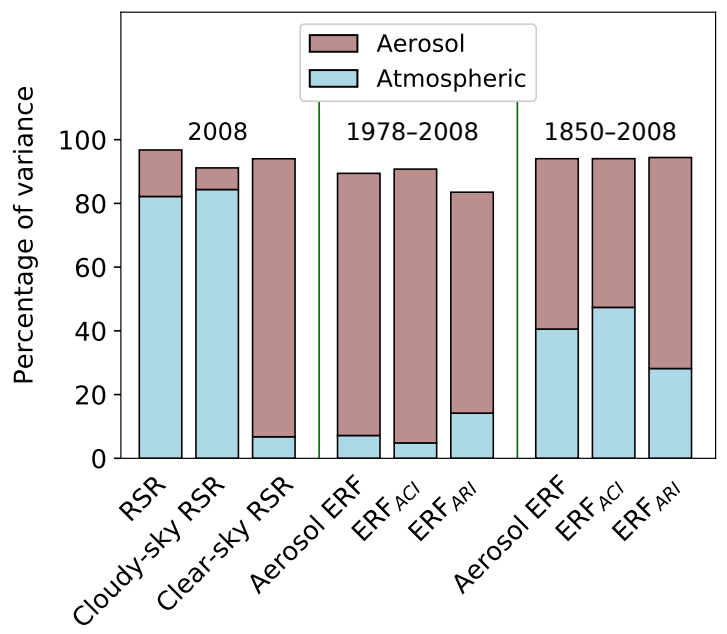

Figure 9. The relative contributions from atmospheric and aerosol parameters to variance in ToA radiative fluxes and aerosol effective radiative forcing over the 1978-2008 and 1850-2008 periods.

tainty will inform our understanding of how to best observationally constrain the uncertainty. We identified regions of substantial aerosol ERF (ensemble mean stronger than around $-2.5 \mathrm{~W} \mathrm{~m}^{-2}$ ) for more in-depth analysis (Table 3 and Fig. 10). Emulators of regional-mean aerosol ERF and its components were created so that the key causes of variance in each region could be identified (Fig. 11).

The main causes of regional aerosol ERF uncertainty are often those parameters that cause global mean uncertainty. However, there are substantial differences between regions. Some parameters are important causes of global
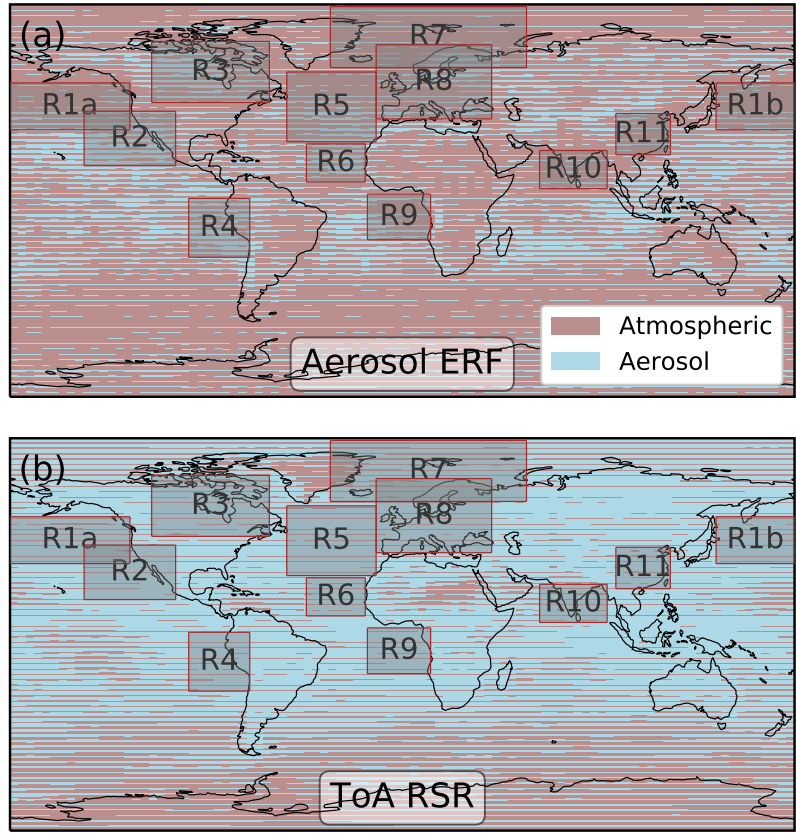

Figure 10. Maps of contributions to variance in (a) 1850-2008 aerosol ERF and (b) present-day (2008) ToA RSR from atmospheric and aerosol parameters. Each pixel contains a box that is shaded in proportion to the amount of variance caused by each source of uncertainty.

mean aerosol ERF uncertainty because they cause a small amount (at least $5 \%$ ) of the uncertainty in nearly all regions. For example, the DMS parameter causes around $5 \%$ of the aerosol ERF variance in most regions and consequentially causes around $15 \%$ of the global mean variance. The cloud radiation parameter Rad_Mcica_Sigma (which causes nearly $30 \%$ of the industrial-period aerosol ERF variance) also causes aerosol ERF variance in most regions. But the amount of regional aerosol ERF variance accounted for by this parameter ranges from less than $3 \%$ (R9) to around $35 \%$ (R2, R3, R4).

Other parameters are important causes of global mean aerosol ERF uncertainty despite being important causes of uncertainty in only around half of the regions examined. For example, the Sea_Spray parameter (which causes nearly $20 \%$ of the global mean aerosol ERF variance) is by far the largest source (around $60 \%$ ) of aerosol ERF variance in the North Pacific (R1) and causes between 10 and $30 \%$ of the variance in several other marine regions. However, in tropical marine regions (R6 and R10) and regions containing continental land mass (R3, R8 and R11) Sea_Spray causes less than $3 \%$ of the aerosol ERF variance. The land-based regions (R3, R8, R11) are also where the cloud updraft parameter Sig_W causes aerosol ERF variance. The importance of Sig_W over continents suggests cloud albedo is most sensitive to uncertainty in updraft velocity in the most polluted re- 
Table 3. Latitude and longitude boundaries for regions R1-R11. Some regional averages are filtered to include only marine or non-marine data.

\begin{tabular}{lllrr}
\hline Region & Description & Filter & Latitudes & Longitudes \\
\hline R1 & North Pacific & Marine & 32.5 to 54 & 144 to -125 \\
R2 & East Pacific stratocumulus deck & Marine & 16 to 41 & -146 to -104 \\
R3 & Canada & All & 45 to 73 & -115 to -61 \\
R4 & South-east Pacific stratocumulus deck & Marine & -26 to 1 & -98 to -70 \\
R5 & North Atlantic & Marine & 27 to 59 & -53 to -12 \\
R6 & South-east North Atlantic & Marine & 8.5 to 26 & -44 to -17 \\
R7 & Arctic & Marine & 61 to 89 & -33 to 57 \\
R8 & Europe & All & 37.5 to 71.5 & -12 to 41 \\
R9 & South-east Atlantic stratocumulus deck & Marine & -18 to 3 & -16 to 13 \\
R10 & North Indian Ocean & Marine & 5.5 to 23 & 63 to 94 \\
R11 & China & Land & 21 to 40 & 98 to 123 \\
\hline
\end{tabular}
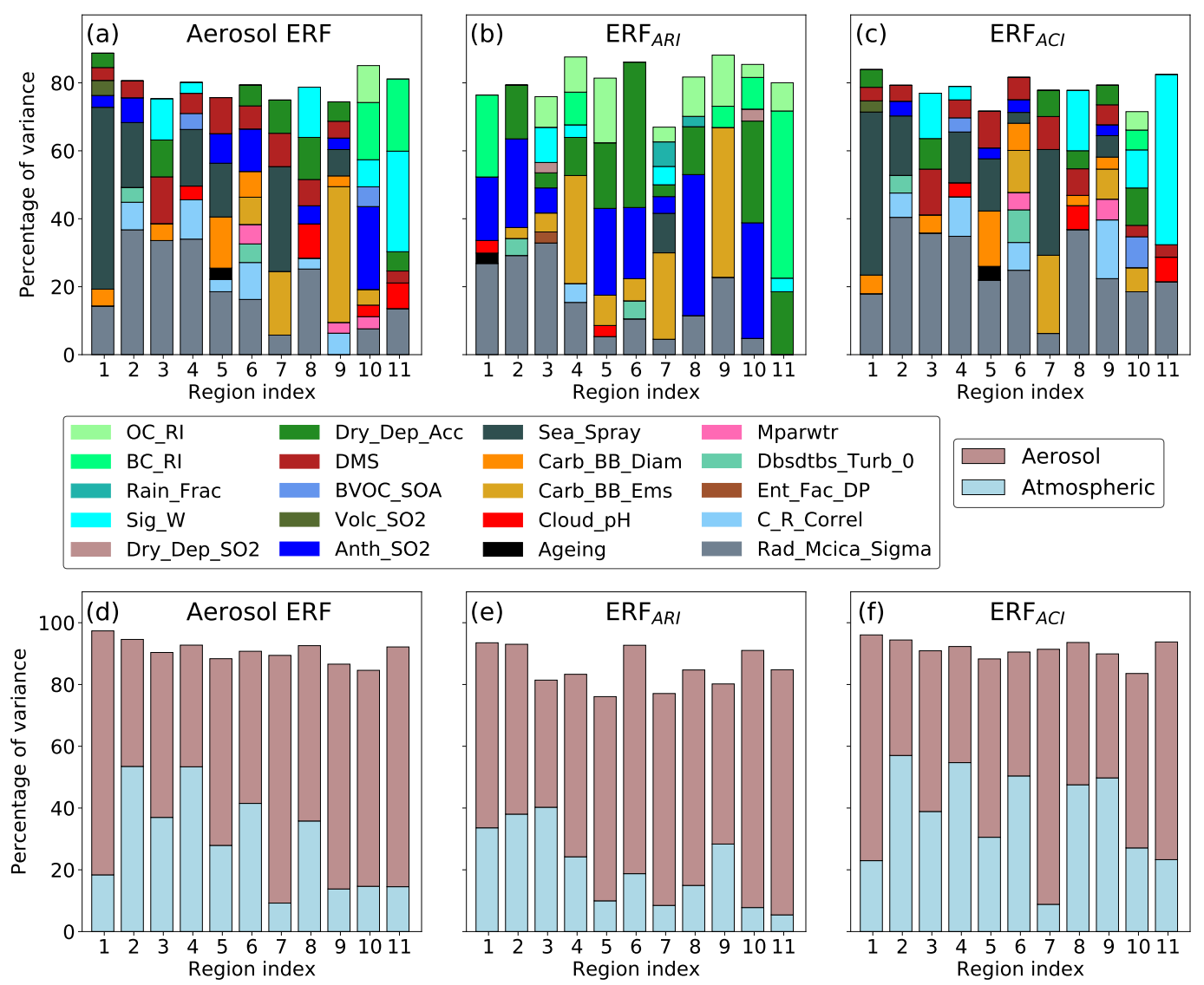

Figure 11. Sources of variance $(\mathbf{a}, \mathbf{b}, \mathbf{c})$ and grouped atmospheric and aerosol contributions to variance (d, e, f) for 1850-2008 annual mean (a, d) aerosol ERF, (b, e) $\mathrm{ERF}_{\mathrm{ARI}}$ and $(\mathbf{c}, \mathbf{f}) \mathrm{ERF}_{\mathrm{ACI}}$ for the 11 regions defined in Table 3 and highlighted in Fig. 10.

gions where cloud droplet concentrations are updraft-limited (Reutter et al., 2009; Sullivan et al., 2016).

Anth_SO2 makes its greatest contribution to aerosol ERF uncertainty in tropical marine regions (R6 and R10) by causing uncertainty in $\mathrm{ERF}_{\mathrm{ARI}}$. The Anth_SO2 parameter also causes up to $40 \%$ of the $\mathrm{ERF}_{\mathrm{ARI}}$ variance near anthropogenic sources (R3 and R8) and up to $30 \%$ in outflow regions (R1,
$\mathrm{R} 2$, R5). However, these substantial causes of $\mathrm{ERF}_{\mathrm{ARI}}$ variance translate into small (less than $10 \%$ ) causes of aerosol ERF variance in most regions. The aerosol deposition parameter (Dry_Dep_Acc) also causes more of the regional $\mathrm{ERF}_{\mathrm{ARI}}$ variance (up to $45 \%$ ) than regional aerosol ERF variance (less than 15\%). However, despite being an important cause of 1850-2008 aerosol ERF uncertainty in sev- 
eral regions, the dry-deposition parameter is not an important cause of global mean aerosol ERF uncertainty over this period (Fig. 4c).

The importance of carbonaceous aerosol parameters (Carb_BB_Ems, Carb_BB_Diam, BC_RI and OC_RI) as causes of aerosol ERF uncertainty is highly region dependent. Uncertainty in the emission flux of carbonaceous aerosols Carb_BB_Ems causes between 25 and $45 \%$ of the $\mathrm{ERF}_{\mathrm{ARI}}$ variance in and near biomass burning regions (R4, R7 and R9). However, this only translates into a cause of aerosol ERF uncertainty in regions R7 and R9 where the Carb_BB_Ems parameter also causes uncertainty in $\mathrm{ERF}_{\mathrm{ACI}}$. Uncertainty in the size of emitted carbonaceous absorbing aerosols (Carb_BB_Diam) is more important as a cause of uncertainty in $\mathrm{ERF}_{\mathrm{ACI}}$ than in $\mathrm{ERF}_{\mathrm{ARI}}$ because it determines the capacity for carbonaceous aerosols to act as cloud condensation nuclei. Therefore, Carb_BB_Diam predominantly causes aerosol ERF variance (up to $15 \%$ ) in the cloudiest regions (R1, R5, R6 and R9). Uncertainty in the radiative properties of carbonaceous aerosols (BC_RI and OC_RI) collectively causes $\mathrm{ERF}_{\mathrm{ARI}}$ variance in almost all regions. However, uncertainty in aerosol ERF is affected by these parameters only over China (R11) and near to India (R10). Over China the anthropogenic emission parameter (Anth_SO2) is surpassed by the BC_RI and OC_RI parameters as causes of $\mathrm{ERF}_{\mathrm{ARI}}$ and aerosol ERF uncertainty, despite carbonaceous aerosols making up a relatively small proportion of aerosol emissions in these regions (Granier et al., 2011). The BC_RI parameter causes around $50 \%$ of the $\mathrm{ERF}_{\text {ARI vari- }}$ ance and around $25 \%$ of the variance in aerosol ERF in China. However, anthropogenic emissions do cause uncertainty in ERF $_{\text {ARI }}$ and aerosol ERF in the Pacific (an outflow region for Chinese emissions). Near India, uncertainty in BC_RI and OC_RI cause around 30 and $10 \%$ of the aerosol ERF variance respectively and cause a smaller amount (between 5 and $10 \%$ ) of variance in each of the forcing components. Despite being important sources of forcing uncertainty at the regional level, Carb_BB_Diam is the only parameter related to carbonaceous aerosols which causes uncertainty in global, annual mean aerosol ERF.

Figure $11 \mathrm{~d}-\mathrm{f}$ show that atmospheric parameters combined can cause up to around $50 \%$ of the regional aerosol ERF variance despite causing only around $30 \%$ of the global mean aerosol ERF variance. However, there are multiple regions where uncertainty in the physical atmosphere parameters causes less than $20 \%$ of the aerosol ERF variance. Where atmospheric parameters are an important source of regional aerosol ERF uncertainty, the Rad_Mcica_Sigma parameter is almost always the most important. On its own, uncertainty in Rad_Mcica_Sigma causes over $20 \%$ of the aerosol ERF variance in coastal Pacific regions (R2 and R4) as well as continental regions (R3 and R8). The atmospheric parameter controlling the accretion rate of aerosols by raindrops (C_R_Correl) causes around $10 \%$ of the aerosol ERF variance in several tropical or sub-tropical regions off the west- ern coast of continents (R2, R4, R6 and R9). These are all regions of persistent stratocumulus cloud where cloud albedo is highly susceptible to changes in aerosol concentrations and size distributions. The clear- and cloudy-air mixing parameter Dbsdtbs_Turb_0 causes between 5 and $10 \%$ of the variance in aerosol ERF and its components in the Northern Hemisphere regions of persistent stratocumulus cloud (R2 and R6) but not in Southern Hemisphere regions (R4 and R9). This suggests that the relatively polluted Northern Hemisphere stratocumulus clouds are more sensitive to the sub-grid mixing of clear- and cloudy air masses. In tropical regions (R6, R9 and R10) the convective parameter Mparwtr causes a small amount ( 3 to $5 \%$ ) of the aerosol ERF variance. This parameter alters the timing of precipitation and therefore affects cloud and aerosol amount, and the $\mathrm{ERF}_{\mathrm{ACI}}$ near the Equator, where convective instability and precipitation are greatest. The regions where physical atmosphere parameters cause the least aerosol ERF variance are either near to anthropogenic emission sources (R9, R10 and R11) or downwind of them (R1 and R7).

These results show that the relative importance of individual parameters as sources of uncertainty differs between regions. However, the most important causes of global mean aerosol ERF uncertainty also cause uncertainty at the regional level.

\subsection{Observational constraint of the aerosol ERF uncertainty}

\subsubsection{Effect of ToA RSR constraint on aerosol ERF uncertainty}

We now explore the extent to which present-day measurements of global mean ToA RSR could in principle help to constrain the change in flux between two time periods (the aerosol ERF), which was previously explored by Lohmann and Ferrachat (2010), who perturbed four physical atmosphere parameters. We expect some constraint of aerosol ERF uncertainty based on the common causes of uncertainty in ToA RSR and aerosol ERF. Observational constraint of a model output variable can lead to constraint of the uncertain parameters. Therefore, when two model output variables share common causes of uncertainty, we can expect that constraint of one output will lead to constraint of the other. Our approach of drawing large samples of 1 million parameter combinations from model emulators (using uniform pdfs for each parameter, Sect. 2.3) enables this link through the uncertain parameters to be understood, which is not possible just from a perturbed parameter ensemble alone (e.g. Lohmann and Ferrachat, 2010).

Our analysis reveals substantial overlap in the combinations of parameters causing uncertainty in 1850-2008 aerosol ERF and present-day ToA RSR. The parameters Rad_Mcica_Sigma, Sea_Spray, C_R_Correl and Sig_W account for about $60 \%$ of the aerosol ERF uncertainty and 
about $80 \%$ of the ToA flux uncertainty. It is important to note that it is irrelevant for the observational constraint process that the ToA flux is much larger than the aerosol ERF. The important factor is that their uncertainties are caused by common uncertain parameters, so constraint of one of them will constrain the other through the constraint of the plausible parameter ranges and relationships.

Figure 12 shows the effect of constraining the modelled present-day global, annual mean RSR to within $\pm 0.25 \mathrm{~W} \mathrm{~m}^{-2}$ of $98.3 \mathrm{~W} \mathrm{~m}^{-2}$, the multi-year average of observations from the Clouds and the Earth's Radiant Energy System (CERES; Loeb et al., 2009). The $\pm 0.25 \mathrm{~W} \mathrm{~m}^{-2}$ represents within-CERES product uncertainty (Loeb et al., 2012) and neglects multiple other sources of satellite observational uncertainty (Loeb et al., 2009; Hartmann et al., 2013). We also neglect uncertainty caused by unknown model structural errors (Goldstein and Rougier, 2004; Sexton et al., 2012; Stier et al., 2013), observation representativeness errors (Schutgens et al., 2017) and the emulators themselves (Oakley and O'Hagan, 2004) which are of the same order of magnitude as the observational uncertainty. Therefore, our RSR observational constraint provides an upper bound on the potential reduction in aerosol ERF uncertainty. This tight constraint eliminates $97 \%$ of the model variants, and the observationally constrained RSR range is less than $2 \%$ of the original unconstrained range. Consequently, the smaller set of model variants also predicts reasonably constrained 1978 and 1850 RSR ranges (Fig. 12a). However, despite reducing the plausible parameter space by $97 \%$ and the RSR range by $98 \%$, the impact on the aerosol ERF uncertainty is more modest (Fig. 12b and c). The effect of applying the RSR observational constraint is to rule out 1850-2008 aerosol ERF values lower than around $-2.4 \mathrm{~W} \mathrm{~m}^{-2}$, which represents around $15 \%$ of the original aerosol ERF range $\left(-2.7,-0.7 \mathrm{~W} \mathrm{~m}^{-2}\right)$. However, the $95 \%$ credible range is only reduced by around $10 \%$ because the distribution of aerosol ERFs in the constrained sample is skewed towards weaker forcings and the upper bound of the credible interval $\left(-0.6 \mathrm{~W} \mathrm{~m}^{-2}\right)$ is larger (Table 4). This reduction in aerosol ERF range is much less than the $56 \%$ reduction found by Lohmann and Ferrachat (2010) based on a set of 169 perturbed parameter simulations (compared to our 1 million model variants). We discuss the reasons for this modest reduction in aerosol ERF uncertainty in Sect. 3.5.2 and 3.5.3.

\subsubsection{Constraining the relationships between the aerosol ERF and uncertain parameters}

Figure 13 shows how aerosol ERF is related to the values of the four main causes of aerosol ERF uncertainty before and after applying the observational constraint. There are clear relationships between the aerosol ERF and the individual parameters, but they are highly uncertain (even in the constrained sample) because there are many compensating errors among the other parameters (i.e. many ways to combine the parameters to get the same ToA RSR but very different aerosol ERF, Fig. 12). This diversity of credible model variants would be overlooked had we perturbed parameters individually, as is the case with one-at-a-time perturbation experiments (e.g. Gettleman, 2015).

For each of the 1 million model variants in our unconstrained sample, individual parameter values were drawn from uniform distributions with ranges defined by the expertelicited pdfs. Therefore, prior to applying the observational constraint, the model variants were evenly dispersed across every two-dimensional parameter sub-space. We are therefore able to quantify the effect of the observational constraint on the plausibility of individual and combined parameter values.

The cloud radiation parameter Rad_Mcica_Sigma is negatively correlated with the ToA radiative flux, and this leads to a positive correlation with aerosol ERF: increasing its value decreases the simulated cloud albedo and hence the ToA RSR. But ToA RSR is more sensitive to Rad_Mcica_Sigma in the present-day atmosphere than in the pre-industrial (because higher aerosol concentrations increase the cloud albedo), so increasing the parameter value weakens the aerosol ERF. Figure 13 shows that low values of Rad_Mcica_Sigma (less than around 0.4 in the scaled range 0 to 1$)$ are inconsistent with the observed RSR. The proportion of model variants with Rad_Mcica_Sigma values less than 0.4 drops from $40 \%$ in the unconstrained sample to just $8 \%$ in the constrained case. In other words, the observational constraint suggests the plausible lower limit of this parameter is higher than we assumed in our expert elicitation. We can therefore state that the strongest aerosol ERFs are also implausible (as shown in Fig. 12) because they are associated with low values of Rad_Mcica_Sigma.

Figure 13 also shows that the aerosol ERF is weaker for larger Sea_Spray and DMS values. An abundance of natural aerosols increases background (pre-industrial) atmospheric aerosol concentrations and limits the influence of anthropogenic aerosol emissions on clouds and radiation (Carslaw et al., 2013). Figure 13 shows that the observed ToA radiative flux is more consistent with low emissions of natural aerosols (the density of Sea_Spray values larger than 0.5 decreases from 50 to $44 \%$ after constraint of the ToA flux). The decreased likelihood of higher natural aerosol emissions in the constrained sample suggests that the weakest aerosol ERF values are less congruent with observed ToA RSR. However, there remain many observationally plausible model variants with high natural aerosol emissions.

The largest values of the cloud updraft parameter (Sig_W) are also less plausible in the constrained sample (Fig. 13; $27 \%$ of the sample are larger than 0.7 , instead of $30 \%$ ). This suggests that present-day RSR observations are more consistent with lower vertical velocities, but the largest values cannot be ruled out completely because of the way that other compensating parameters affect RSR. Lower values of Sig_W weaken the aerosol ERF by reducing cloud droplet 

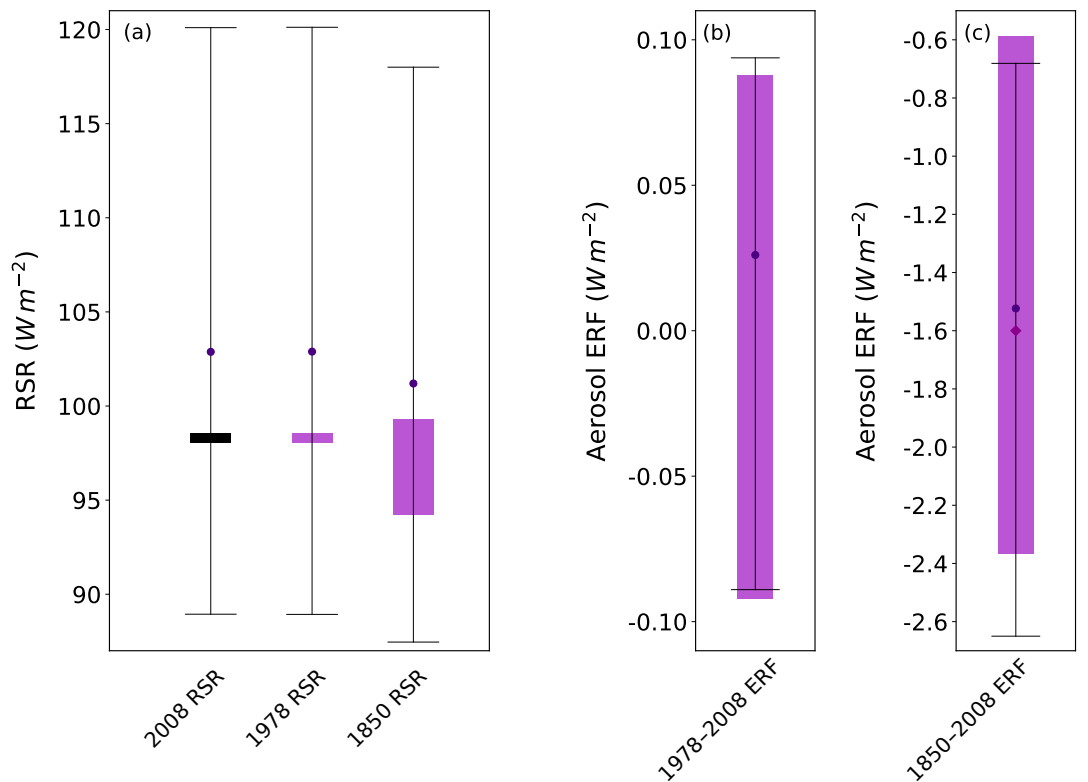

Figure 12. (a) Observationally constrained present-day ToA RSR and the values of 1978 and 1850 ToA RSR and (b) 1978-2008 and (c) 1850-2008 aerosol ERF values from matching model variants. For each output variable the black lines show $95 \%$ credible intervals of the unconstrained 1-million-member sample of model variants. The black box contains all model variants within $\pm 0.25 \mathrm{~W} \mathrm{~m}{ }^{-2}$ of the CERES-observed global annual mean present-day ToA RSR value. Purple boxes represent the $95 \%$ credible intervals of values obtained using model variants (parameter combinations) in the observationally constrained sample. Output from the simulation with all parameters set to their median values is shown as dots. The median 1850-2008 aerosol ERF from the observationally constrained sample is displayed as a diamond.

Table 4. Present-day ToA RSR constraints and the resulting $95 \%$ credible intervals of 1850 RSR and 1850-2008 aerosol ERF (W m ${ }^{-2}$ ) for the unconstrained and constrained samples.

\begin{tabular}{lrrrrr}
\hline Constraint & Sample size & 2008 RSR & 1850 RSR & $1850-2008$ ERF & $\begin{array}{r}1850-2008 \\
\text { ERF credible } \\
\text { range }\end{array}$ \\
& & & & & \\
\hline Unconstrained & 1000000 & $(88.9,120.1)$ & $(87.5,118.0)$ & $(-2.65,-0.68)$ & 1.97 \\
CERES $\left(98.3 \pm 0.25 \mathrm{~W} \mathrm{~m}^{-2}\right)$ & 20127 & $(98.05,98.55)$ & $(94.2,99.3)$ & $(-2.37,-0.59)$ & 1.78 \\
CERES North Pacific & 108493 & $(89.6,106.8)$ & $(88.0,105.1)$ & $(-2.25,-0.53)$ & 1.72 \\
$\left(162.8 \pm 3.3 \mathrm{~W} \mathrm{~m}^{-2}\right)$ & 4699 & $(98.1,98.5)$ & $(95.7,97.8)$ & $(-2.30,-0.56)$ & 1.74 \\
Combined constraint & & & & & \\
\hline
\end{tabular}

concentrations primarily in the present-day polluted atmosphere, because cloud droplet activation is more sensitive to Sig_W in the present-day atmosphere than in the aerosollimited pre-industrial atmosphere. Therefore, observational constraint of ToA radiative flux reduces the likelihood of weak aerosol ERFs through a constraint of the distribution of Sig_W values.

\subsubsection{Constraining the relationships between uncertain parameters}

Figure 13 also shows the important parameter interdependencies revealed by observationally constraining the ToA radiative flux. The Rad_Mcica_Sigma and Sea_Spray parameters are positively correlated in the observationally constrained sample. For example, a modelled ToA RSR consistent with observations can be achieved using high values of Rad_Mcica_Sigma (which decreases cloud albedo) and relatively high values of Sea_Spray (which increases cloud albedo). In other words, these parameters have compensating effects on the ToA radiative flux. The same compensation applies to the aerosol ERF: the weakest ERFs in our pdf (larger than around $-1 \mathrm{~W} \mathrm{~m}^{-2}$ ) are associated with high Rad_Mcica_Sigma and high Sea_Spray values. However, the RSR and aerosol ERF depend on these two parameters in quite different ways. Higher Rad_Mcica_Sigma values weaken the aerosol ERF by reducing the present-day ToA RSR, whilst higher Sea_Spray values weaken the aerosol 


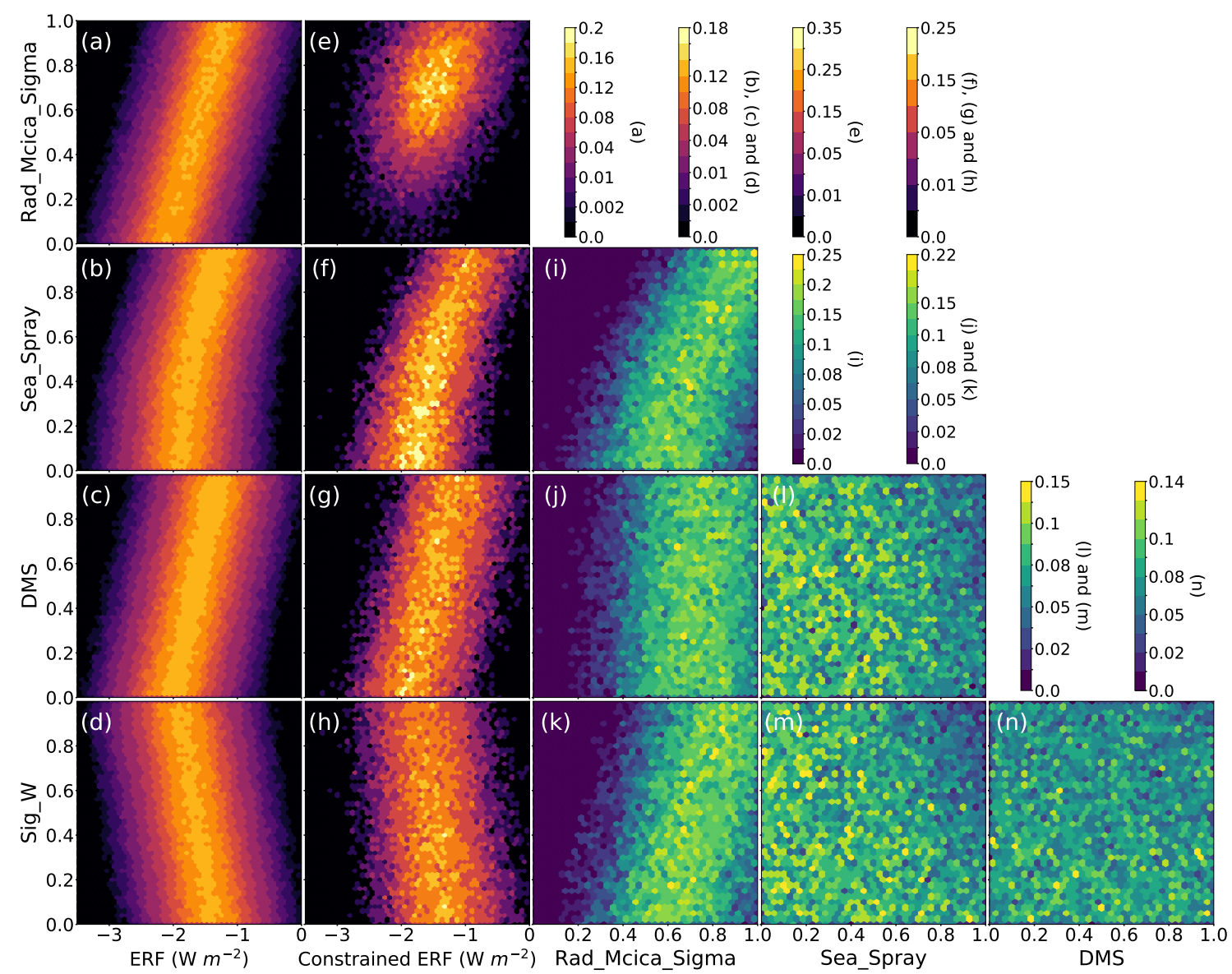

Figure 13. Probability density distributions of aerosol ERF and the parameters Rad_Mcica_Sigma, Sea_Spray, DMS and Sig_W in the unconstrained sample (first column, a-d) and in the sample constrained to match the observed global annual mean RSR (second column, e-h). Probability density distributions of parameter values are shown for the constrained sample (i-n). Colour bars labelled a-n correspond with the sub-figures and show the percentage of each sample within each pixel. Some colour bars apply to multiple panels.

ERF by increasing present-day RSR. Hence, constraining the relationship between the two largest sources of aerosol ERF uncertainty using observations of present-day RSR has not drastically reduced the aerosol ERF uncertainty.

The cloud droplet activation parameter (Sig_W) is also positively correlated with Rad_Mcica_Sigma in the observationally constrained sample (Fig. 13). As with sea spray emissions, higher values of Sig_W increase cloud albedo and compensate for the effect of high Rad_Mcica_Sigma values on ToA RSR. These parameters both exert a greater influence on present-day cloud radiative properties; in the case of Sig_W, cloud radiative properties are more susceptible to this parameter in the present-day simulations because cloud droplet activation is more likely to be updraftlimited (rather than aerosol-limited) in an anthropogenically polluted atmosphere. Therefore, in contrast to the Sea_Spray and Rad_Mcica_Sigma relationship, the Sig_W and Rad_Mcica_Sigma parameters have additive (not compensating) effects on aerosol ERF. Parameters with additive effects on the aerosol ERF are more susceptible to the ef- fects of model equifinality. Therefore, the relationship between aerosol ERF and Sea_Spray is better constrained than the relationship between aerosol ERF and Sig_W.

The Sig_W and Sea_Spray parameters both act to counter the effect of Rad_Mcica_Sigma on cloud albedo in the constrained sample. Therefore, the density of model variants with simultaneously large (above around 0.6) Sig_W and Sea_Spray values is lower in the constrained sample (down from 16 to $11 \%$ ). No such restrictions apply to simultaneously small values (less than 0.4 ) of these two parameters. In fact the proportion of simultaneously small Sig_W and Sea_Spray in the sample increases from 16 to $19 \%$ after applying the constraint which rules out other parts of parameter space. This suggests that in simulations with low natural aerosol emissions and low cloud droplet activation efficiency, there are multiple other contributing factors keeping the ToA RSR in agreement with observations. For example, by limiting the mixing rates of clear and cloudy air masses, a low value of the Dbsdtbs_Turb_0 parameter (an important source of ToA RSR uncertainty) can compensate 
for the decrease in cloud droplet concentrations caused by a low value of the cloud droplet activation parameter. A replacement source of aerosols large enough to act as cloud condensation nuclei is also required to compensate for low natural aerosol emissions. There are multiple ways in which this could be achieved. For example, a low value of the drydeposition velocity parameter Dry_Dep_Acc (known to be important for cloud active aerosol concentrations; Lee et al., 2013) increases the atmospheric lifetime of aerosols, allowing them to grow in size and activate to form cloud droplets, even in a low-activation-efficiency simulations.

The DMS parameter has no obvious relationships with the other main sources of aerosol ERF uncertainty in the constrained sample. This is despite DMS affecting aerosol ERF in the same regions as other key parameters and causing aerosol ERF uncertainty through a similar mechanism to Sea_Spray. In other words, higher values of DMS and Sea_Spray suppress the aerosol ERF by increasing background (1850) aerosol concentrations. Therefore, the value of the DMS parameter is more likely ( $54 \%$ of the time) to be small (lower than 0.5) when the value of Sea_Spray is high (above 0.8). In summary, model variants with high values of both of the important natural aerosol emission parameters are less likely to be consistent with the observed ToA RSR.

These results highlight the importance of understanding the potential causes of equifinality when interpreting results from such a complex model (Beven and Freer, 2001). Reducing the remaining uncertainty in global mean aerosol ERF will require observations which further constrain the relationships between aerosol ERF and the key sources of uncertainty.

\subsubsection{Regional constraint of global mean aerosol ERF uncertainty}

Our overall aim is to constrain the uncertainty in global annual mean aerosol ERF because the total ERF is commonly used to quantify the multi-model diversity in historically forced changes to the climate (Myhre et al., 2013; p. 661). However, regional variations in aerosol forcing can be important drivers of climate variability (Chalmers et al., 2012; Booth et al., 2012; Bollasina et al., 2013; Shindell et al., 2013; Kirtman et al., 2013) and can contribute to global mean forcing uncertainty in complex ways (Regayre et al., 2015). Therefore we now use satellite observations of the North Pacific (region R1; latitude: $32-54^{\circ} \mathrm{N}$; longitude: $125^{\circ} \mathrm{W}-144^{\circ} \mathrm{E}$; the largest regional contribution to global mean aerosol ERF) ToA RSR from July to further constrain annual, global mean aerosol ERF uncertainty.

The regionally averaged CERES-observed ToA RSR is $162.8 \mathrm{~W} \mathrm{~m}^{-2}$ (CERES, 2017) with an estimated uncertainty of $\pm 2 \%$ (Hartmann et al., 2013, 2.3.1, p. 181). The original sample of 1 million model variants is reduced to around $10 \%$ by applying the North Pacific July mean RSR constraint and to just $0.5 \%$ of the original sample by applying both the global mean and North Pacific constraints together (Table 4). In combination with the global mean observation, the North Pacific RSR constraint has little additional effect on the credible forcing ranges $\left(-2.30\right.$ to $-0.56 \mathrm{~W} \mathrm{~m}^{-2}$ compared to -2.37 to $-0.59 \mathrm{~W} \mathrm{~m}^{-2}$ ). The range of plausible aerosol ERF values has been further reduced by only around $2 \%$. This suggests that the regional observation has provided little additional constraint on the relationships between aerosol ERF and the main sources of uncertainty (Fig. S1 in the Supplement).

\section{Conclusions}

We sampled the uncertainty in 18 aerosol and 9 atmospheric parameters within a single global climate model, identified the important causes of aerosol ERF uncertainty and constrained this uncertainty using ToA radiative flux measurements. The credible range of aerosol ERF values in our original sample of 1 million model variants is -2.65 to $-0.68 \mathrm{~W} \mathrm{~m}^{-2}$ when we assume the parameter values have equal likelihood of being at any point in the elicited ranges. The aerosol ERF uncertainty decreases when we constrain global mean ToA RSR ( -2.37 to $\left.-0.59 \mathrm{~W} \mathrm{~m}^{-2}\right)$ and when we constrain both North Pacific and global RSR $(-2.30$ to $-0.56 \mathrm{~W} \mathrm{~m}^{-2}$ ). These results suggest that additional constraint of aerosol ERF uncertainty could be achieved using multiple regional ToA flux observations. However, a greater reduction $(25 \%)$ in the aerosol ERF uncertainty (95\% credible range, -2.18 to $-0.71 \mathrm{~W} \mathrm{~m}^{-2}$ ) can be achieved by applying probability distributions to the parameters based on expert elicitation (Sect. 3.1). These results suggest that the strongest aerosol ERF values (about $20 \%$ of the unconstrained range) can be considered implausible based on expert opinion and observational evidence.

Our results reveal that aerosol parameters take a dominant role over atmospheric parameters as the leading cause of aerosol ERF uncertainty over the industrial period and in recent decades. Atmospheric parameters cause the majority (over $80 \%$ ) of the uncertainty in present-day ToA reflected short-wave radiation but only around $30 \%$ of the aerosol ERF variance. A handful of the aerosol and atmospheric parameters that we have examined dominate the uncertainty in global mean aerosol ERF. A cloud radiation parameter, natural aerosol emissions and model process parameters that affect cloud droplet formation and removal are the key sources of global mean aerosol ERF uncertainty over the industrial period. The most important causes of 1978-2008 aerosol ERF uncertainty are model process parameters controlling the deposition rates of aerosols and aerosol precursor gases. Our analysis shows that uncertainties in aerosol parameters are of secondary importance for determining presentday ToA radiative flux, but they are a much more important source (over half) of the uncertainty in the change in atmo- 
spheric radiative balance (the aerosol ERF) on multi-century and multi-decadal timescales.

Uncertainty in the ERF $\mathrm{ARI}_{\mathrm{AR}}$ component of forcing $(-0.19$ to $0.13 \mathrm{~W} \mathrm{~m}^{-2}$ ) is largely caused by parameters related to carbonaceous aerosols. However, these parameters contribute little to uncertainty in the total aerosol ERF, which is dominated by uncertainty in the $\mathrm{ERF}_{\mathrm{ACI}}$ component of forcing ( -2.20 to $0.61 \mathrm{~W} \mathrm{~m}^{-2}$ ) in our analyses. In our simulations light-absorbing aerosols heat the local atmosphere above clouds, suppress convection and affect cloud cover. However, we do not represent all of the processes that determine the magnitude of carbonaceous aerosol forcing. For example, we neglect the deposition of absorbing aerosols onto high-albedo land surfaces. Therefore, despite the large uncertainties in our carbonaceous aerosol parameters, our global mean $E F_{A R I}$ uncertainty range does not span the range of values found by Bond et al. (2013).

At the regional level, uncertainty in aerosol ERF is predominantly caused by the same parameters that cause global mean aerosol ERF uncertainty. Some parameters such as the cloud radiation parameter Rad_Mcica_Sigma and the natural aerosol emission parameter DMS are important for global mean aerosol ERF uncertainty because they cause at least a small amount $(5 \%)$ of the uncertainty in nearly all regions. Other important causes of global mean aerosol ERF uncertainty (Sea_Spray, Sig_W and Anth_SO2) are amongst the largest causes of the aerosol ERF uncertainty in some regions (marine, polluted and polluted-marine regions respectively) but cause very little of the uncertainty elsewhere. We show that because carbonaceous aerosols only cause aerosol ERF uncertainty in high-emission months and in regions close to emission sources, most of the carbonaceous aerosol parameters (with the exception of Carb_BB_Diam) are not important for global, annual mean aerosol ERF uncertainty.

One important source of $\mathrm{ERF}_{\mathrm{ACI}}$ uncertainty we did not include in our study is the autoconversion rate of cloud drops into raindrops (Michibata and Takemura, 2015; Malavelle et al., 2017; Toll et al., 2017). Were we to include the autoconversion rate as an additional source of uncertainty, the credible range of aerosol ERFs would be larger. If the autoconversion rate were an important cause of uncertainty in both ToA flux and aerosol ERF, the constraint on ERF uncertainty would likely be stronger. However, if autoconversion were to affect ToA flux and aerosol ERF in different ways or to different extents, then including this additional source of uncertainty may amplify the equifinality problem by introducing another important degree of freedom. The additional uncertainty from autoconversion could be constrained to a large extent using collocated observations of changes in liquid water path, cloud fraction and aerosol concentrations. We expect such observations of cloud-aerosol relationships will be particularly useful for constraining a model's ability to represent transitions between cloud regimes, and we plan to test their efficacy as constraints in the next phase of our research.
A well-constrained multi-decadal historical aerosol ERF would provide more policy-relevant information on nearterm temperature change than industrial-period ERF, which remains challenging to constrain (Hawkins et al., 2017). Constraining recent-decadal aerosol ERF uncertainty may prove to be an easier task than constraining uncertainty in industrial-period forcing because the multi-decadal uncertainty is caused by model process parameters that could be observed directly. Global mean aerosol ERF in recent decades has depended more linearly on changing anthropogenic emissions than industrial-period aerosol ERF. Therefore, the causes of aerosol ERF uncertainty in recent decades (1978-2008) are model deposition rates (model process parameters) and anthropogenic emissions, whilst the 1850-2008 aerosol ERF is most sensitive to natural aerosol emissions (which collectively cause around $63 \%$ of the aerosol contribution to $\mathrm{ERF}_{\mathrm{ACI}}$ variance). The magnitude of global mean aerosol forcing on the decadal timescale depends on the combination of uncertain positive and negative regional forcings (Regayre et al., 2015; Fig. 5). Hence, projects designed to improve our understanding of the state and behaviour of aerosol-cloud-radiation interactions on regional scales and within specific cloud regimes will aid efforts to constrain global mean forcing. In summary, reducing the uncertainty in aerosol ERF will require a much deeper understanding of how the uncertainties in state variables and model parameters, as well as the relationships between them, combine at the regional and global levels in complex global climate models. We develop our understanding of the potential to constrain regional aerosol ERF uncertainty using multiple observable quantities (e.g. aerosol optical depth and aerosol concentrations) in Johnson et al. (2018).

Climate models are routinely tuned to match present-day ToA radiative fluxes (in conjunction with multiple other observational metrics) so as to ensure accurate characterisation of the state of the atmosphere (Kay et al., 2012; Mauritsen et al., 2012; Flato et al., 2013; Hourdin et al., 2017). Our sensitivity analysis shows that the ToA radiative flux and the 1850-2008 aerosol ERF share common sources of uncertainty. Therefore, observational constraint of ToA flux representing just $0.5 \%$ of the model's prior range has reduced the $95 \%$ credible interval of our simulated global mean aerosol ERF by around $10 \%$. These results counter the belief that observations of ToA reflected short-wave radiation should not constrain the aerosol ERF (because RSR values are 2 orders of magnitude larger than the aerosol ERF). However, comprehensively sampling model uncertainty provides a densely populated multi-dimensional parameter space which connects the observed value (RSR) to the model variable of interest (the aerosol ERF). The RSR observation constrains the parameter space and in doing so constrains the aerosol ERF uncertainty. However, we caution that the constraint will only be robust if all relevant parameters affecting RSR have been explored. 
Our results show that the plausible ranges of individual parameters as well as the relationships between them are constrained by present-day observations, thereby substantially reducing the model parameter space that can be considered observationally plausible. We use RSR observations with a small observational uncertainty to demonstrate their potential use as a constraint on aerosol ERF uncertainty. However, despite a very large reduction in plausible parameter space, the effectiveness of the observational constraint is modest because it is hampered by compensating effects between multiple uncertain parameters, which results in multiple equally plausible solutions (sometimes referred to as "equifinality"; Beven and Freer, 2001; Lee et al., 2016). The challenge now is to find optimum combinations of constraints that overcome this problem using a more robust framework that accounts for all quantifiable sources of uncertainty (Sexton et al., 2012; Williamson et al., 2013). For aerosol ERF this means simultaneously constraining aerosols, clouds, and radiation state variables as well as the relationships between them so as to constrain uncertainty in the change of state on multiple timescales.

By highlighting how different parameters and processes control the change in planetary radiative balance in a single state-of-the-art model, our results suggest that compensating effects between groups of uncertain parameters and associated processes are one important reason why uncertainty in aerosol ERF has persisted through several generations of climate model development. Given the huge range of interacting processes and uncertainties, it is highly unlikely that single observational constraints (as employed in so-called emergent constraint studies; e.g. Cherian et al., 2014) will enable a robust reduction in aerosol ERF uncertainty. Our results, combined with those of other studies that have comprehensively sampled model uncertainties (Calisto et al., 2014; Lee et al., 2016; Ghan et al., 2016), suggest that reducing aerosol ERF uncertainty further will require the simultaneous application of a large number of observational constraints (Sanderson, 2010; Sexton et al., 2012; Collins et al., 2012; Reddington et al., 2017) covering polluted and pristine environments (Carslaw et al., 2013; Hamilton et al., 2014) and targeting the specific processes and relationships identified here.

Code availability. Code can be made available upon request from the corresponding author.

Data availability. Data can be made available upon request from the corresponding author. The authors welcome use of the perturbed parameter ensemble for advancing climate research.

Supplement. The supplement related to this article is available online at: https://doi.org/10.5194/acp-18-9975-2018-supplement.
Author contributions. LAR tested the model configuration, designed and prepared the ensemble and analysed the results. LAR and KSC wrote the article. All authors contributed to the analysis and interpretation of results. KJP, MY, LAR, KSC, JSJ and NB helped prepare the model configuration that served as the template for the ensemble. LAR and JSJ designed the experiments. All simulations were created by LAR. MY advised on computational aspects of the ensemble creation. The screening of atmospheric parameters was conducted by LAR, DMHS and KSC. LAR and JSJ elicited probability density functions of all aerosol parameters, and $\mathrm{KSC}$, NB, KJP, MY and LAL participated (alongside many other experts) in the formal elicitation process.

Competing interests. The authors declare that they have no conflict of interest.

Acknowledgements. Leighton Regayre was funded by a Natural Environment Research Council (NERC) doctoral training grant and a CASE studentship with the UK Met Office Hadley Centre. Ben Booth was supported by the Joint UK DECC-Defra Met Office Hadley Centre Climate Programme (GA01101). Kenneth Carslaw is currently a Royal Society Wolfson Merit Award holder. We acknowledge funding from NERC under grants AEROS, ACIDPRUF, GASSP and A-CURE (NE/G006172/1, NE/I020059/1, NE/J024252/1 and NE/P013406/1). This work and its contributors (Jill Johnson, David Sexton and Kenneth Carslaw) were supported by the UK-China Research \& Innovation Partnership Fund through the Met Office Climate Science for Service Partnership (CSSP) China as part of the Newton Fund. This work used the ARCHER UK National Supercomputing Service (http://www.archer.ac.uk, last access: 9 July 2018). ARCHER project allocation n02FREEPPE and the Leadership Project allocation n02-CCPPE were used to create the ensemble. The authors appreciate the commitment given by participants in the expert elicitation, particularly Colin Johnson, Ben Johnson, James Mollard, Steven Turnock, Douglas Hamilton, Anja Schmidt, Cat Scott, Robin Stevens, Ed Butt, Carly Reddington, Matthew Woodhouse, Dominik Spracklen and Oliver Wild.

Edited by: Ashu Dastoor

Reviewed by: Steven J. Ghan and one anonymous referee

\section{References}

Allen, R. J., Norris, J. R., and Kovilakam, M.: Influence of anthropogenic aerosols and the Pacific Decadal Oscillation on tropical belt width, Nat. Geosci., 7, 270-274, https://doi.org/10.1038/ngeo2091, 2014.

Andreae, M. O., Jones, C. D., and Cox, P. M.: Strong present-day aerosol cooling implies a hot future, Nature, 435, 1187-1190, https://doi.org/10.1038/nature03671, 2005.

Andrianakis, I., Vernon, I., McCreesh, N., McKinley, T. J., Oakley, J. E., Nsubuga, R. N., Goldstein, M., and White, R. G.: History matching of a complex epidemiological model of human immunodeficiency virus transmission by using vari- 
ance emulation, J. Roy. Stat. Soc. C-App., 66, 717-740, https://doi.org/10.1111/rssc.12198, 2017.

Barker, H. W. and Räisänen, P.: Radiative sensitivities for cloud structural properties that are unresolved by conventional GCMs, Q. J. Roy. Meteor. Soc., 131, 3103-3122, https://doi.org/10.1256/qj.04.174, 2005.

Barrett, T. J., Brattström, S., Sharma, S., Worthy, D. E. J., and Novelli, P.: The role of scavenging in the seasonal transport of black carbon and sulfate to the Arctic, Geophys. Res. Lett., 38, L16805, https://doi.org/10.1029/2011GL048221, 2011.

Bellucci, A., Mariotti, A., and Gualdi, S.: The role of forcings in the Twentieth-Century North Atlantic multidecadal variability: The 1940-1975 North Atlantic cooling case study, J. Climate, 30, 7317-7337, https://doi.org/10.1175/JCLI-D-16-0301.1, 2017.

Beven, K. and Freer, J.: Equifinality, data assimilation, and uncertainty estimation in mechanistic modelling of complex environmental systems using the GLUE methodology, J. Hydrol., 249, 11-29, https://doi.org/10.1016/S0022-1694(01)00421-8, 2001.

Bollasina, M. A., Ming, Y., and Ramaswamy, V.: Earlier onset of the Indian monsoon in the late twentieth century: The role of anthropogenic aerosols, Geophys. Res. Lett., 40, 3715-3720, https://doi.org/10.1002/grl.50719, 2013.

Bond, T. C., Doherty, S. J., Fahey, D. W., Forster, P. M., Berntsen, T., DeAngelo, B. J., Flanner, M. G., Ghan, S., Kärcher, B., Koch, D., Kinne, S., Kondo, Y., Quinn, P. K., Sarofim, M. C., Schultz, M. G., Schulz, M., Venkataraman, C., Zhang, H., Zhang, S., Bellouin, N., Guttikunda, S. K., Hopke, P. K., Jacobson, M. Z., Kaiser, J. W., Klimont, Z., Lohmann, U., Schwarz, J. P., Shindell, D., Storelvmo, T., Warren, S. G., and Zender, C. S.: Bounding the role of black carbon in the climate system: A scientific assessment, J. Geophys. Res.-Atmos., 118, 5380-5552, https://doi.org/10.1002/jgrd.50171, 2013.

Booth, B. B. B., Dunstone, N. J., Halloran, P. R., Andrews, T., and Bellouin, N.: Aerosols implicated as a prime driver of twentiethcentury North Atlantic climate variability, Nature, 484, 228-232, https://doi.org/10.1038/nature10946, 2012.

Boucher, O., Randall, D., Artaxo, P., Bretherton, C., Feingold, G., Forster, P., Kerminen, V. M., Kondo, Y., Liao, H., Lohmann, U., Rasch, P., Satheesh, S. K., Sherwood, S., Stevens, B., and Zhang, X. Y.: Clouds and Aerosols, in: Climate Change 2013: The Physical Science Basis. Contribution of Working Group I to the Fifth Assessment Report of the Intergovernmental Panel on Climate Change, edited by: Stocker, T. F., Qin, D., Plattner, G. K., Tignor, M., Allen, S. K., Boschung, J., Nauels, A., Xia, Y., Bex, V., and Midgley, P. M., Cambridge University Press, Cambridge, United Kingdom and New York, USA, 2013.

Boutle, I. A., Abel, S. J., Hill, P. G., and Morcrette, C. J.: Spatial variability of liquid cloud and rain: observations and microphysical effects, Q. J. Roy. Meteor. Soc., 140, 585-594, https://doi.org/10.1002/qj.2140, 2014.

Browse, J., Carslaw, K. S., Arnold, S. R., Pringle, K., and Boucher, O.: The scavenging processes controlling the seasonal cycle in Arctic sulphate and black carbon aerosol, Atmos. Chem. Phys., 12, 6775-6798, https://doi.org/10.5194/acp12-6775-2012, 2012.

Calisto, M., Folini, D., Wild, M., and Bengtsson, L.: Cloud radiative forcing intercomparison between fully coupled CMIP5 models and CERES satellite data, Ann. Geophys., 32, 793-807, https://doi.org/10.5194/angeo-32-793-2014, 2014.
Carslaw, K. S., Lee, L. A., Reddington, C. L., Pringle, K. J., Rap, A., Forster, P. M., Mann, G. W., Spracklen, D. V., Woodhouse, M., Regayre, L. A., and Pierce, J. R.: Large contribution of natural aerosols to uncertainty in indirect forcing, Nature, 503, 67-71, https://doi.org/10.1038/nature12674, 2013.

Carslaw, K. S., Gordon, H., Hamilton, D. S., Johnson, J. S., Regayre, L. A., and Yoshioka, M.: Aerosols in the preindustrial atmosphere, Curr. Clim. Change Rep., 3, 1-15, https://doi.org/10.1007/s40641-017-0061-2, 2017.

Carslaw, K. S., Johnson, J. S., Regayre, L. A., and Lee, L. A.: Climate models are uncertain, but we can do something about it, EOS, 99, https://doi.org/10.1029/2018EO093757., 2018.

CERES: Clouds and the Earth's Radiant Energy System, available at: https://ceres.larc.nasa.gov/order_data.php, last access: August 2017.

Chalmers, N., Highwood, E. J., Hawkins, E., Sutton, R., and Wilcox, L. J.: Aerosol contribution to the rapid warming of nearterm climate under RCP 2.6, Geophys. Res. Lett., 39, L18709, https://doi.org/10.1029/2012GL052848, 2012.

Cherian, R., Quass, J., Salzmann, M., and Wild, M.: Pollution trends over Europe constrain global aerosol forcing as simulated by climate models, Geophys. Res. Lett., 41, 2176-2181, https://doi.org/10.1002/2013GL058715, 2014.

Collins, M., Booth, B. B. B., Bhaskaran, B., Harris, G. R., Murphy, J. M., Sexton, D. M. H., and Webb, M. J.: Climate model errors, feedbacks and forcings: a comparison of perturbed physics and multi-model ensembles, Clim. Dynam., 36, 1737-1766, 2010.

Collins, M., Chandler, R. E., Cox, P. M., Huthnance, J. M., Rougier, J., and Stephenson, D. B.: Quantifying future climate change, Nat. Clim. Change, 2, 403-409, 2012.

Collins, M., Knutti, R., Arblaster, J., Dufresne, J. L., Fichefet, D., Friedlingstein, P., Gao, X., Gutowski, W. J., Johns, T., Krinner, G., Shongwe, M., Tebaldi, C., Weaver, A. J., and Wehner, M.: Long-term Climate Change: Projections Commitments and Irreversibility, in: Climate Change 2013: The Physical Science Basis. Contribution of Working Group I to the Fifth Assessment Report of the Intergovernmental Panel on Climate Change, edited by: Stocker, T. F., Qin, D., Plattner, G. K., Tignor, M., Allen, S. K., Boschung, J., Nauels, A., Xia, Y., Bex, V., and Midgley, P. M., Cambridge University Press, Cambridge, United Kingdom and New York, NY, USA, 2013.

Croft, B., Pierce, J. R., Martin, R. V., Hoose, C., and Lohmann, U.: Uncertainty associated with convective wet removal of entrained aerosols in a global climate model, Atmos. Chem. Phys., 12, 10725-10748, https://doi.org/10.5194/acp-12-107252012, 2012.

Dunstone, N. J., Smith, D. M., Booth, B. B. B., Hermanson, L., and Eade, R.: Anthropogenic aerosol forcing of Atlantic tropical storms, Nat. Geosci., 6, 534-539, https://doi.org/10.1038/ngeo1854, 2013.

Flato, G., Marotzke, J., Abiodun, B., Braconnot, P., Chou, S. C., Collins, W., Cox, P., Driouech, F., Emori, S., Eyring, V., Forest, C., Glecker, P., Guilyardi, E., Jacob, C., Kattsov, V., Reason, C., and Rumukainen, M.: Evaluation of Climate Models, in: Climate Change 2013: The Physical Science Basis. Contribution of Working Group I to the Fifth Assessment Report of the Intergovernmental Panel on Climate Change, edited by: Stocker, T. F., Qin, D., Plattner, G. K., Tignor, M., Allen, S. K., Boschung, J., Nauels, A., Xia, Y., Bex, V., and Midgley, P. M., Cambridge Uni- 
versity Press, Cambridge, United Kingdom and New York, USA, 2013.

Gantt, B., Johnson, M. S., Crippa, M., Prévôt, A. S. H., and Meskhidze, N.: Implementing marine organic aerosols into the GEOS-Chem model, Geosci. Model Dev., 8, 619-629, https://doi.org/10.5194/gmd-8-619-2015, 2015.

Gettelman, A.: Putting the clouds back in aerosol-cloud interactions, Atmos. Chem. Phys., 15, 12397-12411, https://doi.org/10.5194/acp-15-12397-2015, 2015.

Gettleman, A., Kay, J. E., and Fasullo, J. T.: Spatial decomposition of climate feedbacks in the Community Earth System Model, J. Climate, 26, 3544-3561, https://doi.org/10.1175/JCLI-D-1200497.1, 2013.

Ghan, S. J.: Technical Note: Estimating aerosol effects on cloud radiative forcing, Atmos. Chem. Phys., 13, 9971-9974, https://doi.org/10.5194/acp-13-9971-2013, 2013.

Ghan, S. J., Wang, M., Zhang, S., Ferrachat, S., Gettleman, A., Griesfeller, J., Kipling, Z., Lohmann, U., Morrison, H., Neubauer, D., Partridge, D. G., Stier, P., Takemura, T., Wang, H., and Zhang, K.: Challenges in constraining anthropogenic aerosol effects on cloud radiative forcing using present-day spatiotemporal variability, Proc. Natl. Acad. Sci. USA, 113, 5804-5811, https://doi.org/10.1073/pnas.1514036113, 2016.

Gnanadesikan, A., Scott, A. A., Pradal, M. A., and Seviour, W. J. M.: Regional responses to black carbon aerosols: The importance of air-sea interaction, J. Geophys. Res.-Atmos., 122, 12982-12999, https://doi.org/10.1002/2017JD027589, 2017.

Golaz, J. C., Horowitz, L. W., and II, H. L.: Cloud tuning in a coupled climate model: impact on 20th century warming, Geophys. Res. Lett., 40, 2246-2251, https://doi.org/10.1002/grl.50232, 2013.

Goldstein, M. and Rougier, J.: Probabilistic formulations for transferring inferences from mathematical models to physical systems, Siam, 26, 467-487, https://doi.org/10.1137/S106482750342670X, 2004.

Gordon, H., Kirkby, J., Baltensperger, U., Bianchi, F., Breitenlechner, M., Curtius, J., Dias, A., Dommen, J., Donahue, N. M., Dunne, E. M., Duplissy, J., Ehrhart, S., Flagan, R. C., Frege, C., Fuchs, C., Hansel, A., Hoyle, C. R., Kulmala, M., Kurten, A., Lehtipalo, K., Makhmutov, V., Molteni, U., Rissanen, M. P., Stozkhov, Y., Trostl, J., Tsagkogeorgas, G., Wagner, R., Williamson, C., Wimmer, D., Winkler, P. M., Yan, C., and Carslaw, K. S.: Causes and importance of new particle formation in the present-day and preindustrial atmospheres, J. Geophys. Res.-Atmos., 122, 8739-8760, https://doi.org/10.1002/2017JD026844, 2017.

Granier, C., Bessagnet, B., Bond, T., D’Angiola, A., van der Gon, H. D., Frost, G. J., Heli, A., Kaiser, J. W., Kinne, S., Kilmont, Z., Kloster, S., Lamarque, J. F., Liousse, C., Masui, T., Meleux, F., Mieville, A., Ohara, T., Raut, J. C., Riahi, K., Schultz, M. G., Smith, S. J., Thompson, A., van Aardenne, J., van der Werf, G. R., and van Vuuren, D. P.: Evolution of anthropogenic and biomass burning emissions of air pollutants at global and regional scales during the 1980-2010 period, Climatic Change, 109, 163-190, https://doi.org/10.1007/s10584011-0154-1, 2011.

Gryspeerdt, E., Quaas, J., Ferrachat, S., Gettelman, A., Ghan, S., Lohmann, U., Morrison, H., Neubauer, D., Partridge, D. G., Stier, P., Takemura, T., Wang, H., Wang, M., and
Zhang, K.: Constraining the instantaneous aerosol influence on cloud albedo, Proc. Natl. Acad. Sci. USA, 114, 4899-4904, https://doi.org/10.1073/pnas.1617765114, 2017.

Guo, L., Highwood, E. J., Shaffrey, L. C., and Turner, A. G.: The effect of regional changes in anthropogenic aerosols on rainfall of the East Asian Summer Monsoon, Atmos. Chem. Phys., 13, 1521-1534, https://doi.org/10.5194/acp-13-1521-2013, 2013.

HadCRUT4: Met Office Hadley Centre observations dataset, HadCRUT4, available at: https://www.metoffice.gov.uk/hadobs/ hadcrut4, last access: October 2017.

HadGEM3: Met Office climate prediction model: HadGEM3 family, available at: http://www.metoffice.gov.uk/research/ modelling-systems/unified-model/climate-models/hadgem3, last access: March 2017.

Haerter, J. O., Roeckner, E., Tomassini, L., and von Storch, J. S.: Parametric uncertainty effects on aerosol radiative forcing, Geophys. Res. Lett., 36, L15707, https://doi.org/10.1029/2009GL039050, 2009.

Hamilton, D. S., Lee, L. A., Pringle, K. J., Reddington, C. L. S., Spracklen, D. V., and Carslaw, K. S.: Occurrence of pristine aerosol on a polluted planet, Proc. Natl. Acad. Sci. USA, 111, 18466-18471, https://doi.org/10.1073/pnas.1415440111, 2014.

Hartmann, D. L., A. M. G. Klein T., Rusticucci, M., Alexander, L. V., Brönnimann, S., Charabi, Y., Dentener, F. J., Dlugokencky, E. J., Easterling, D. R., Kaplan, A., Soden, B. J., Thorne, P. W., Wild, M., and Zhai, P. M.: Observations: Atmosphere and Surface, in: Climate Change 2013: The Physical Science Basis. Contribution of Working Group I to the Fifth Assessment Report of the Intergovernmental Panel on Climate Change, edited by: Stocker, T. F., Qin, D., Plattner, G. K., Tignor, M., Allen, S. K., Boschung, J., Nauels, A., Xia, Y., Bex, V., and Midgley, P. M., Cambridge University Press, Cambridge, United Kingdom and New York, NY, USA, 2013.

Hawkins, E., Ortega, P., Suckling, E., Schurer, A., Hergl, G., Jones, P., Joshi, M., Osborne, T., Masson-Delmotte, V., Mignot, J., Thorne, P., and Jan van Oldenborgh, G.: Estimating changes in global temperature since the preindustrial period, B. Am. Meteorol. Soc., 98, 1841-1856, https://doi.org/10.1175/BAMS-D-160007.1, 2017.

Hetzel, J.: Package 'Trapezoid', available at: https: //cran.r-project.org/web/packages/trapezoid/trapezoid.pdf (last access: 9 July 2018), 2012.

Hourdin, F., Mauritsen, T., Gettleman, A., Golaz, J., Balaji, V., Duan, Q., Folini, D., Klocke, D. J. D., Qian, Y., Rauser, F., Rio, C., Tomassini, L., Watanabe, M., and Williamson, D.: The art and science of climate model tuning, B. Am. Meteorol. Soc., 98, 589-602, https://doi.org/10.1175/BAMS-D-15-00135.1, 2017.

Johnson, J. S., Cui, Z., Lee, L. A., Gosling, J. P., Blyth, A. M., and Carslaw, K. S.: Evaluating uncertainty in convective cloud microphysics using statistical emulation, J. Adv. Model. Earth Sy., 7, 162-187, https://doi.org/10.1002/2014MS000383, 2015.

Johnson, J. S., Regayre, L. A., Yoshioka, M., Pringle, K. J., Lee, L. A., Sexton, D., Rostron, J., Booth, B. B. B., and Carslaw, K. S.: The importance of comprehensive parameter sampling and multiple observations for robust constraint of aerosol radiative forcing, Atmos. Chem. Phys. Discuss., https://doi.org/10.5194/acp2018-174, in review, 2018.

Karydis, V. A., Tsimpidi, A. P., Bacer, S., Pozzer, A., Nenes, A., and Lelieveld, J.: Global impact of mineral dust on cloud droplet 
number concentration, Atmos. Chem. Phys., 17, 5601-5621, https://doi.org/10.5194/acp-17-5601-2017, 2017.

Kasoar, M., Voulgarakis, A., Lamarque, J.-F., Shindell, D. T., Bellouin, N., Collins, W. J., Faluvegi, G., and Tsigaridis, K.: Regional and global temperature response to anthropogenic $\mathrm{SO}_{2}$ emissions from China in three climate models, Atmos. Chem. Phys., 16, 9785-9804, https://doi.org/10.5194/acp-169785-2016, 2016.

Kay, J. E., Hillman, B. R., Klein, S. A., Zhang, Y., Medeiros, B., Pincus, R., Gettleman, A., Eaton, B., Boyle, J., Marchand, R., and Ackerman, T. P.: Exposing Global Cloud Biases in the Community Atmosphere Model (CAM) Using Satellite Observations and Their Corresponding Instrument Simulators, J. Climate, 25, 5190-5207, https://doi.org/10.1175/JCLI-D-11-00469.1, 2012.

Khain, A. P., Ovtchinnikov, M., Pinsky, M., Potrovsky, A., and Krugliak, H.: Notes on state-of-the-art numerical modeling of cloud microphysics, Atmos. Res., 55, 159-224, https://doi.org/10.1016/S0169-8095(00)00064-8, 2000.

Kim, D., Chin, M., Yu, H. B., Diehl, T., Tan, Q., Kahn, R. A., Tsigaridis, K., Bauer, S. E., Takemura, T., Pozzoli, L., Bellouin, N., Schulz, M., Peyridieu, S., Chedin, A., and Koffi, B.: Sources, sinks and transatlantic transport of North African dust aerosol: A multimodel analysis and comparison with remote sensing data, J. Geophys. Res.-Atmos., 119, 6259-6277, https://doi.org/10.1002/2013JD021099, 2014.

Kipling, Z., Stier, P., Johnson, C. E., Mann, G. W., Bellouin, N., Bauer, S. E., Bergman, T., Chin, M., Diehl, T., Ghan, S. J., Iversen, T., Kirkevåg, A., Kokkola, H., Liu, X., Luo, G., van Noije, T., Pringle, K. J., von Salzen, K., Schulz, M., Seland, Ø., Skeie, R. B., Takemura, T., Tsigaridis, K., and Zhang, K.: What controls the vertical distribution of aerosol? Relationships between process sensitivity in HadGEM3-UKCA and inter-model variation from AeroCom Phase II, Atmos. Chem. Phys., 16, 2221-2241, https://doi.org/10.5194/acp-16-2221-2016, 2016.

Kirtman, B., Power, S. B., Adedoyin, J. A., Boer, G. J., Bojariu, R., Camilloni, I., Doblas-Reyes, F. J., Fiore, A. M., Kimoto, M., Meehl, G. A., Prather, M., Sarr, A., Schär, C., Sutton, R., van Oldenborgh, G. J., Vecchi, G., and Wang, H. J.: Near-term Climate Change: Projections and Predictability, in: Climate Change 2013: The Physical Science Basis. Contribution of Working Group I to the Fifth Assessment Report of the Intergovernmental Panel on Climate Change, edited by: Stocker, T. F., Qin, D., Plattner, G. K., Tignor, M., Allen, S. K., Boschung, J., Nauels, A., Xia, Y., Bex, V., and Midgley, P. M., Cambridge University Press, Cambridge, United Kingdom and New York, NY, USA, 2013.

Knutti, R., Krähenmann, S., Frame, D. J., and Allen, M. R.: Comment on "Heat capacity, time constant, and sensitivity of earth's climate system" by SE Schwartz, J. Geophys. Res.-Atmos., 113, 1984-2012, https://doi.org/10.1029/2007JD009473, 2008.

Knutti, R., Masson, D., and Gettleman, A.: Climate model genealogy: Generation CMIP5 and how we got there, Geophys. Res. Lett., 40, 1194-1199, https://doi.org/10.1002/grl.50256, 2013.

Koffi, B., Schulz, M., Breon, F. M., Dentener, F., Steensen, B. M., Griesfeller, J., Winker, D., Balkanski, Y., Bauer, S. E., Bellouin, N., Berntsen, T., Bian, H. S., Chin, M., Diehl, T., Easter, R., Ghan, S., Hauglustaine, D. A., Iversen, T., Kirkevag, A., Liu, X. H., Lohmann, U., Myhre, G., Rasch, P., Seland, O., Skeie, R. B., Steenrod, S. D., Stier, P., Tackett, J., Takemura, T., Tsi- garidis, K., Vuolo, M. R., Yoon, J., and Zhang, K.: Evaluation of the aerosol vertical distribution in global aerosol models through comparison against CALIOP measurements: AeroCom phase II results, J. Geophys. Res.-Atmos., 121, 7254-7283, https://doi.org/10.1002/2015JD024639, 2016.

Kooperman, G. J., Pritchard, M. S., Ghan, S. J., Wang, M., Somerville, R. C. J., and Russell, L. M.: Constraining the influence of natural variability to improve estimates of global aerosol indirect effects in a nudged version of the Community Atmosphere Model 5, J. Geophys. Res., 117, 1-16, https://doi.org/10.1029/2012JD018588, 2012.

Korhonen, H., Carslaw, K. S., Spracklen, D. V., Mann, G. W., and Woodhouse, M. T.: Influence of oceanic dimethyl sulfide emissions on cloud condensation nuclei concentrations and seasonality over the remote Southern Hemisphere oceans: A global model study, J. Geophys. Res., 113, 16, 2008.

Kretzschmar, J., Salzmann, M., Mülmenstädt, J., Boucher, O., and Quass, J.: Comment on Rethinking the Lower Bound on Aerosol Radiative Forcing, J. Climate, 30, 6579-6584, https://doi.org/10.1175/JCLI-D-16-0668.1, 2017.

Lacagnina, C., Hasekamp, O. P., Huisheng, B., Curci, G., Myhre, G., van Noije, T., Schulz, M., Skeie, R. B., Takemura, T., and Zhang, K.: Aerosol single-scattering albedo over the global oceans: Comapring PARASOL retrievals with AERONET, OMI, and AeroCom models estiamtes, J. Geophys. Res.-Atmos., 120, 9814-9836, https://doi.org/10.1002/2015JD023501, 2015.

Lamarque, J.-F., Bond, T. C., Eyring, V., Granier, C., Heil, A., Klimont, Z., Lee, D., Liousse, C., Mieville, A., Owen, B., Schultz, M. G., Shindell, D., Smith, S. J., Stehfest, E., Van Aardenne, J., Cooper, O. R., Kainuma, M., Mahowald, N., McConnell, J. R., Naik, V., Riahi, K., and van Vuuren, D. P.: Historical (1850-2000) gridded anthropogenic and biomass burning emissions of reactive gases and aerosols: methodology and application, Atmos. Chem. Phys., 10, 7017-7039, https://doi.org/10.5194/acp-10-7017-2010, 2010.

Lebo, Z. J. and Feingold, G.: On the relationship between responses in cloud water and precipitation to changes in aerosol, Atmos. Chem. Phys., 14, 11817-11831, https://doi.org/10.5194/acp-1411817-2014, 2014.

Lee, L. A., Carslaw, K. S., Pringle, K. J., Mann, G. W., and Spracklen, D. V.: Emulation of a complex global aerosol model to quantify sensitivity to uncertain parameters, Atmos. Chem. Phys., 11, 12253-12273, https://doi.org/10.5194/acp-11-122532011, 2011.

Lee, L. A., Carslaw, K. S., Pringle, K. J., and Mann, G. W.: Mapping the uncertainty in global $\mathrm{CCN}$ using emulation, Atmos. Chem. Phys., 12, 9739-9751, https://doi.org/10.5194/acp12-9739-2012, 2012.

Lee, L. A., Pringle, K. J., Reddington, C. L., Mann, G. W., Stier, P., Spracklen, D. V., Pierce, J. R., and Carslaw, K. S.: The magnitude and causes of uncertainty in global model simulations of cloud condensation nuclei, Atmos. Chem. Phys., 13, 8879-8914, https://doi.org/10.5194/acp-13-8879-2013, 2013.

Lee, L. A., Reddington, C. L., and Carslaw, K. S.: On the relationship between aerosol model uncertainty and radiative forcing uncertainty, Proc. Natl. Acad. Sci. USA, 113, 5820-5827, https://doi.org/10.1073/pnas.1507050113, 2016. 
Liu, X. H. and Wang, J. A.: How important is organic aerosol hygroscopicity to aerosol indirect effect?, Environ. Res. Lett., 5, 044010, https://doi.org/10.1088/1748-9326/5/4/044010, 2010.

Liu, Y. and Gupta, H. V.: Uncertainties in hydrologic modeling: Toward an integrated data assimilation framework, Water Resour. Res., 43, 1-17, https://doi.org/10.1029/2006WR005756, 2007.

Loeb, N. G., Wielicki, B. A., Doelling, D. R., Smith, G. L., Keyes, D. F., Kato, S., Manalo-Smith, N., and Wong, T.: Toward Optimal Closure of the Earth's Top-of-Atmosphere Radiation Budget, J. Climate., 22, 748-766, https://doi.org/10.1175/2008JCLI2637.1, 2009.

Loeb, N. G., Kato, S., Su, W., Wong, T., Rose, F. G., Doelling, D. R., Norris, J. R., and Huang, X.: Advances in Understanding Top-ofAtmosphere Radiation Variability from Satellite Observations, Surv. Geophys., 33, 359-385, https://doi.org/10.1007/s10712012-9175-1, 2012.

Lohmann, U.: Why does knowledge of past aerosol forcing matter for future climate change?, J. Geophys. Res.-Atmos., 122, 50215023, https://doi.org/10.1002/2017JD026962, 2017.

Lohmann, U. and Ferrachat, S.: Impact of parametric uncertainties on the present-day climate and on the anthropogenic aerosol effect, Atmos. Chem. Phys., 10, 11373-11383, https://doi.org/10.5194/acp-10-11373-2010, 2010.

Malavelle, F. F., Haywood, J. M., Ones, A. J., Gettleman, A., Larisse, L. C., Bauduin, S., Allan, R. P., Karset, I. H. H., Kristjansson, J. E., Oreopoulos, L., Ho, N. C., Lee, D., Bellouin, N., Boucher, O., Grosvenor, D. P., Carslaw, K. S., Dhomse, S., Mann, G. W., Schmidt, A., and M. E. Hartley, H. C., Dalvi, M., Hill, A. A., Johnson, B. T., Jphnson, C. E., Knight, J. R., Jeff, R., O’Connor, F. M., Partridge, D. G., Stier, P., Myhre, G., Platnick, S., Stephens, G. L., Takahashi, H., and Thordarson, T.: Strong constraints on aerosol-cloud interactions from volcanic eruptions, Nature, 543, 485-491, https://doi.org/10.1038/nature22974, 2017.

Manktelow, P. T., Carslaw, K. S., Mann, G. W., and Spracklen, D. V.: The impact of dust on sulfate aerosol, $\mathrm{CN}$ and $\mathrm{CCN}$ during an East Asian dust storm, Atmos. Chem. Phys., 10, 365-382, https://doi.org/10.5194/acp-10-365-2010, 2010.

Mann, G. W., Carslaw, K. S., Spracklen, D. V., Ridley, D. A., Manktelow, P. T., Chipperfield, M. P., Pickering, S. J., and Johnson, C. E.: Description and evaluation of GLOMAP-mode: a modal global aerosol microphysics model for the UKCA composition-climate model, Geosci. Model Dev., 3, 519-551, https://doi.org/10.5194/gmd-3-519-2010, 2010.

Mann, G. W., Carslaw, K. S., Reddington, C. L., Pringle, K. J., Schulz, M., Asmi, A., Spracklen, D. V., Ridley, D. A., Woodhouse, M. T., Lee, L. A., Zhang, K., Ghan, S. J., Easter, R. C., Liu, X., Stier, P., Lee, Y. H., Adams, P. J., Tost, H., Lelieveld, J., Bauer, S. E., Tsigaridis, K., van Noije, T. P. C., Strunk, A., Vignati, E., Bellouin, N., Dalvi, M., Johnson, C. E., Bergman, T., Kokkola, H., von Salzen, K., Yu, F., Luo, G., Petzold, A., Heintzenberg, J., Clarke, A., Ogren, J. A., Gras, J., Baltensperger, U., Kaminski, U., Jennings, S. G., O'Dowd, C. D., Harrison, R. M., Beddows, D. C. S., Kulmala, M., Viisanen, Y., Ulevicius, V., Mihalopoulos, N., Zdimal, V., Fiebig, M., Hansson, H.-C., Swietlicki, E., and Henzing, J. S.: Intercomparison and evaluation of global aerosol microphysical properties among AeroCom models of a range of complexity, Atmos. Chem. Phys., 14, 4679-4713, https://doi.org/10.5194/acp-14-4679-2014, 2014.
Mauritsen, T., Stevens, B., Roeckner, E., Crueger, T., Esch, M., Giorgetta, M., Haak, H., Jungclaus, J., Klocke, D., Matei, D., Mikolajewicz, U., Notz, D., Pincus, R., Schmidt, H., and Tomassini, L.: Tuning the climate of a global model, J. Adv. Model. Earth Sy., 4, M00A01, https://doi.org/10.1029/2012MS000154, 2012.

Metzger, A., Verheggen, B., Dommen, J., Duplissy, J., Prevot, A. S. H., Weingartner, E., Riipinen, I., Kulmala, M., Spracklen, D. V., Carslaw, K. S., and Baltensperger, U.: Evidence for the role of organics in aerosol particle formation under atmospheric conditions, Proc. Natl. Acad. Sci. USA, 107, 6646-6651, https://doi.org/10.1073/pnas.0911330107, 2010.

Michibata, T. and Takemura, T.: Evaluation of autoconversion schemes in a single model framework with satellite observations, J. Geophys. Res.-Atmos., 120, 1-21, https://doi.org/10.1002/2015JD023818-T, 2015.

Morgan, M. G., Adams, P. J., and Keith, D. W.: Elicitation of expert judgements about aerosol forcing, Climatic Change, 75, 195214, https://doi.org/10.1007/s10584-005-9025-y, 2006.

Myhre, G., Shindell, D., Bréon, F. M., Collins, W., Fuglestvedt, J., Huang, J., Koch, D., Lamarque, J. F., Lee, D., Mendoza, B., Nakajima, T., Robock, A., Stephens, G., Takemura, T., and Zhang, H.: Anthropogenic and Natural Radiative Forcing, in: Climate Change 2013: The Physical Science Basis. Contribution of Working Group I to the Fifth Assessment Report of the Intergovernmental Panel on Climate Change, edited by: Stocker, T. F., Qin, D., Plattner, G. K., Tignor, M., Allen, S. K., Boschung, J., Nauels, A., Xia, Y., Bex, V., and Midgley, P. M., Cambridge University Press, Cambridge, United Kingdom and New York, NY, USA, 2013.

Nam, C., Bony, S., Dufresne, J. L., and Chepfer, H.: The "too few, too bright" tropical low-cloud problem in CMIP5 models, Geophys. Res. Lett., 39, L21801, https://doi.org/10.1029/2012GL053421, 2012.

Neubauer, D., Lohmann, U., Hoose, C., and Frontoso, M. G.: Impact of the representation of marine stratocumulus clouds on the anthropogenic aerosol effect, Atmos. Chem. Phys., 14, 11997 12022, https://doi.org/10.5194/acp-14-11997-2014, 2014.

Oakley, J. E. and O'Hagan, A.: Probabilistic sensitivity analysis of complex models: a Bayesian approach, JRSSB, 66, 751-769, 2004.

Pan, X., Chin, M., Gautam, R., Bian, H., Kim, D., Colarco, P. R., Diehl, T. L., Takemura, T., Pozzoli, L., Tsigaridis, K., Bauer, S., and Bellouin, N.: A multi-model evaluation of aerosols over South Asia: common problems and possible causes, Atmos. Chem. Phys., 15, 5903-5928, https://doi.org/10.5194/acp15-5903-2015, 2015.

Pennell, C. and Reichler, T.: On the effective number of climate models, J. Climate, 24, 2358-2367, 2010.

Petters, M. D. and Kreidenweis, S. M.: A single parameter representation of hygroscopic growth and cloud condensation nucleus activity, Atmos. Chem. Phys., 7, 1961-1971, https://doi.org/10.5194/acp-7-1961-2007, 2007.

Pianosi, F., Beven, K., Freer, J., Hall, J. W., Rougier, J., Stephenson, D. B., and Wagener, T.: Sensitivity analysis of environmental models: A systematic review of practical workflow, Environ. Model. Softw., 79, 214-232, https://doi.org/10.1016/j.envsoft.2016.02.008, 2016. 
Pringle, K. J., Carslaw, K. S., Fan, T., Mann, G. W., Hill, A., Stier, P., Zhang, K., and Tost, H.: A multi-model assessment of the impact of sea spray geoengineering on cloud droplet number, Atmos. Chem. Phys., 12, 11647-11663, https://doi.org/10.5194/acp-12-11647-2012, 2012.

Qian, Y., Yan, H., Zhangshuan, H., Gardar, J., Klein, S., Lucas, D., Neale, R., Rasch, P., Swiller, L., Tannahill, J., Wang, H., Wang, M., and Zhao, C.: Parametric sensitivity analysis of precipitation at global and local scales in the Comunity Atmosphere Model CAM5, J. Adv. Model. Earth Sy., 7, 382-411, https://doi.org/10.1002/2014MS000354, 2015.

Räisänen, P., Barker, H. W., Khairoutdinov, M. F., Li, J., and Randall, D. A.: Stochastic generation of subgrid-scale cloudy columns for large-scale models, Q. J. Roy. Meteor. Soc., 130, 2047-2067, https://doi.org/10.1256/qj.03.99, 2004.

Randles, C. A., Kinne, S., Myhre, G., Schulz, M., Stier, P., Fischer, J., Doppler, L., Highwood, E., Ryder, C., Harris, B., Huttunen, J., Ma, Y., Pinker, R. T., Mayer, B., Neubauer, D., Hitzenberger, R., Oreopoulos, L., Lee, D., Pitari, G., Di Genova, G., Quaas, J., Rose, F. G., Kato, S., Rumbold, S. T., Vardavas, I., Hatzianastassiou, N., Matsoukas, C., Yu, H., Zhang, F., Zhang, H., and $\mathrm{Lu}$, P.: Intercomparison of shortwave radiative transfer schemes in global aerosol modeling: results from the AeroCom Radiative Transfer Experiment, Atmos. Chem. Phys., 13, 2347-2379, https://doi.org/10.5194/acp-13-2347-2013, 2013.

Reddington, C. L., Carslaw, K. S., Spracklen, D. V., Frontoso, M. G., Collins, L., Merikanto, J., Minikin, A., Hamburger, T., Coe, H., Kulmala, M., Aalto, P., Flentje, H., Plass-Dülmer, C., Birmili, W., Wiedensohler, A., Wehner, B., Tuch, T., Sonntag, A., O’Dowd, C. D., Jennings, S. G., Dupuy, R., Baltensperger, U., Weingartner, E., Hansson, H.-C., Tunved, P., Laj, P., Sellegri, K., Boulon, J., Putaud, J.-P., Gruening, C., Swietlicki, E., Roldin, P., Henzing, J. S., Moerman, M., Mihalopoulos, N., Kouvarakis, G., Ždímal, V., Zíková, N., Marinoni, A., Bonasoni, P., and Duchi, R.: Primary versus secondary contributions to particle number concentrations in the European boundary layer, Atmos. Chem. Phys., 11, 12007-12036, https://doi.org/10.5194/acp-11-120072011, 2011.

Reddington, C. L., Carslaw, K. S., Stier, P., Schutgens, N., Coe, H., Liu, D., Allan, J., Browse, J., Pringle, K., Lee, L., Yoshioka, M., Johnson, J., Regayre, L., Spracklen, D., Mann, G., Clarke, A., Hermann, M., Henning, S., Wex, H., Kristensen, T., Leaitch, W., Poeschl, U., Rose, D., Andreae, M., Schmale, J., Kondo, Y., Oshima, N., Schwarz, J., Nenes, A., Andreson, B., Roberts, G., Snider, J., Leck, C., Quinn, P., Chi, X., Ding, A., Jimenez, J., and Zhang, Q.: The Global Aerosol Synthesis and Science Project (GASSP), B. Am. Meteorol. Soc., 8, 1857-1877, https://doi.org/10.1175/BAMS-D-15-00317.1, 2017.

Regayre, L. A., Pringle, K. J., Booth, B. B. B., Lee, L. A., Mann, G. W., Browse, J., Woodhouse, M. T., Rap, A., Reddington, C. L. S., and Carslaw, K. S.: Uncertainty in the magnitude of aerosol-cloud radiative forcing over recent decades, Geophys. Res. Lett., 41, 9040-9049, https://doi.org/10.1002/2014GL062029, 2014.

Regayre, L. A., Pringle, K. J., Lee, L. A., Booth, B. B. B., Rap, A., Browse, J., Mann, G. W., Woodhouse, M. T., Reddington, C. L. S., and Carslaw, K. S.: The climatic importance of uncertainties in regional aerosol-cloud radiative forcings over recent decades, J. Climate., 28, 6589-6607, https://doi.org/10.1175/JCLI-D-15-0127.1, 2015.

Reutter, P., Su, H., Trentmann, J., Simmel, M., Rose, D., Gunthe, S. S., Wernli, H., Andreae, M. O., and Pöschl, U.: Aerosol- and updraft-limited regimes of cloud droplet formation: influence of particle number, size and hygroscopicity on the activation of cloud condensation nuclei (CCN), Atmos. Chem. Phys., 9, 70677080, https://doi.org/10.5194/acp-9-7067-2009, 2009.

Rodrigues, L. F. S., Vernon, I., and Bower, R.: Constraints on galaxy formation models from the galaxy stellar mass function and its evolution, Mon. Not. R. Astron. Soc., 466, 2418-2435, https://doi.org/10.1093/mnras/stw3269, 2017.

Rougier, J.: Ensemble averaging and mean squared error, J. Climate, 29, 8865-8870, https://doi.org/10.1175/JCLI-D-160012.1, 2016.

Saltelli, A., Tarantola, S., and Chan, K. P. S.: A quantitative modelindependent method for global sensitivity analysis of model output, Technometrics, 41, 39-56, https://doi.org/10.2307/1270993, 1999.

Saltelli, A., Chan, K., and Scott, E. M.: Sensitivity Analysis, Wiley, Oxford, UK, 2000.

Samset, B. H., Myhre, G., Herber, A., Kondo, Y., Li, S.-M., Moteki, N., Koike, M., Oshima, N., Schwarz, J. P., Balkanski, Y., Bauer, S. E., Bellouin, N., Berntsen, T. K., Bian, H., Chin, M., Diehl, T., Easter, R. C., Ghan, S. J., Iversen, T., Kirkevåg, A., Lamarque, J.F., Lin, G., Liu, X., Penner, J. E., Schulz, M., Seland, Ø., Skeie, R. B., Stier, P., Takemura, T., Tsigaridis, K., and Zhang, K.: Modelled black carbon radiative forcing and atmospheric lifetime in AeroCom Phase II constrained by aircraft observations, Atmos. Chem. Phys., 14, 12465-12477, https://doi.org/10.5194/acp-1412465-2014, 2014.

Sanderson, B. M.: A multimodel study of parametric uncertainty in predictions of climate response to rising greenhouse gas concentrations., J. Climate., 24, 1362-1377, https://doi.org/10.1175/2010JCLI3498.1, 2010.

Schmidt, A., Ostro, B., Carslaw, K. S., Wilson, M., Thordarson, T., Mann, G. W., and Simmons, A. J.: Excess mortality in Europe following a future Laki-style Icelandic eruption, Proc. Natl. Acad. Sci. USA, 108, 15710-15715, 2011.

Schulz, M., Textor, C., Kinne, S., Balkanski, Y., Bauer, S., Berntsen, T., Berglen, T., Boucher, O., Dentener, F., Guibert, S., Isaksen, I. S. A., Iversen, T., Koch, D., Kirkevåg, A., Liu, X., Montanaro, V., Myhre, G., Penner, J. E., Pitari, G., Reddy, S., Seland, Ø., Stier, P., and Takemura, T.: Radiative forcing by aerosols as derived from the AeroCom present-day and pre-industrial simulations, Atmos. Chem. Phys., 6, 5225-5246, https://doi.org/10.5194/acp6-5225-2006, 2006.

Schutgens, N., Tsyro, S., Gryspeerdt, E., Goto, D., Weigum, N., Schulz, M., and Stier, P.: On the spatio-temporal representativeness of observations, Atmos. Chem. Phys., 17, 9761-9780, https://doi.org/10.5194/acp-17-9761-2017, 2017.

Seinfeld, J. H., Bretherton, C., Carslaw, K. S., Coe, H., DeMott, P. J., Dunlea, E. J., Feingold, G., Ghan, S., Guenther, A. B., Kahn, R., Kraucunas, I., Kreidenweis, S. M., Molina, M. J., Nenes, A., Penner, J. E., Prather, K. A., Ramanathan, V., Ramaswamy, V., Rasch, P. J., Ravishankara, A. R., Rosenfeld, D., Stephens, G., and Wood, R.: Improving our fundamental understanding of the role of aerosol-cloud interactions in the cli- 
mate system, Proc. Natl. Acad. Sci. USA, 113, 5781-5790, https://doi.org/10.1073/pnas.1514043113, 2016.

Sexton, D. M. H., Murphy, J. M., Collins, M., and Webb, M. J.: Multivariate probabilistic projections using imperfect climate models Part I: outline of methodology, Clim. Dynam., 38, 2513-2542, 2012

Sexton, D. M. H., Karmalkar, A., Murphy, J., and Booth, B. B. B.: The elicitation of distributions of parameters in HadGEM3 versions GA4 and GA7 for use in perturbed parameter ensembles, Hadley Centre technical note 101, Met Office, UK, 2018.

Shindell, D. T., Lamarque, J.-F., Schulz, M., Flanner, M., Jiao, C., Chin, M., Young, P. J., Lee, Y. H., Rotstayn, L., Mahowald, N., Milly, G., Faluvegi, G., Balkanski, Y., Collins, W. J., Conley, A. J., Dalsoren, S., Easter, R., Ghan, S., Horowitz, L., Liu, X., Myhre, G., Nagashima, T., Naik, V., Rumbold, S. T., Skeie, R., Sudo, K., Szopa, S., Takemura, T., Voulgarakis, A., Yoon, J.-H., and Lo, F.: Radiative forcing in the ACCMIP historical and future climate simulations, Atmos. Chem. Phys., 13, 2939-2974, https://doi.org/10.5194/acp-13-2939-2013, 2013.

Shiogama, H., Watanabe, M., Yoshimori, M., Yokohata, T., Ogura, T., Annan, J. D., Hargreaves, J. C., Abe, M., Kamae, Y., O’ishi, R., Nobui, R., Emori, S., Nozawa, T., Abe-Ouchi, A., and Kimoto, M.: Perturbed physics ensemble using the MIROC5 coupled atmosphere-ocean GCM without flux corrections: experimental design and results, Clim. Dynam., 39, 3041-3056, https://doi.org/10.1007/s00382-012-1441-x, 2012.

Shrivastava, M., Zhao, C., Easter, R. C., Qian, Y., Zelenyuk, A., Fast, J. D., Liu, Y., Zhang, Q., and Guenther, A.: Sensitivity analysis of simulated SOA loadings using a variance-based statistical approach, J. Adv. Model. Earth Sy., 8, 499-519, https://doi.org/10.1002/2015MS000554, 2016

Smith, S. J., van Aardenne, J., Klimont, Z., Andres, R. J., Volke, A., and Delgado Arias, S.: Anthropogenic sulfur dioxide emissions: 1850-2005, Atmos. Chem. Phys., 11, 1101-1116, https://doi.org/10.5194/acp-11-1101-2011, 2011.

Snedecor, G. W. and Cochran, W. G.: Statistical methods, Iowa State University Press, 8th edn., Ames, Iowa, 1989.

Spracklen, D. V., Pringle, K. J., Carslaw, K. S., Chipperfield, M. P., and Mann, G. W.: A global off-line model of sizeresolved aerosol microphysics: I. Model development and prediction of aerosol properties, Atmos. Chem. Phys., 5, 22272252, https://doi.org/10.5194/acp-5-2227-2005, 2005.

Spracklen, D. V., Carslaw, K. S., Merikanto, J., Mann, G. W., Reddington, C. L., Pickering, S., Ogren, J. A., Andrews, E., Baltensperger, U., Weingartner, E., Boy, M., Kulmala, M., Laakso, L., Lihavainen, H., Kivekäs, N., Komppula, M., Mihalopoulos, N., Kouvarakis, G., Jennings, S. G., O’Dowd, C., Birmili, W., Wiedensohler, A., Weller, R., Gras, J., Laj, P., Sellegri, K., Bonn, B., Krejci, R., Laaksonen, A., Hamed, A., Minikin, A., Harrison, R. M., Talbot, R., and Sun, J.: Explaining global surface aerosol number concentrations in terms of primary emissions and particle formation, Atmos. Chem. Phys., 10, 4775-4793, https://doi.org/10.5194/acp-10-4775-2010, 2010.

Spracklen, D. V., Carslaw, K. S., Pöschl, U., Rap, A., and Forster, P. M.: Global cloud condensation nuclei influenced by carbonaceous combustion aerosol, Atmos. Chem. Phys., 11, 9067-9087, https://doi.org/10.5194/acp-11-9067-2011, 2011a.

Spracklen, D. V., Jimenez, J. L., Carslaw, K. S., Worsnop, D. R., Evans, M. J., Mann, G. W., Zhang, Q., Canagaratna, M. R.,
Allan, J., Coe, H., McFiggans, G., Rap, A., and Forster, P.: Aerosol mass spectrometer constraint on the global secondary organic aerosol budget, Atmos. Chem. Phys., 11, 12109-12136, https://doi.org/10.5194/acp-11-12109-2011, 2011 b.

Stevens, B.: Rethinking the Lower Bound on Aerosol Radiative Forcing, J. Climate, 28, 4794-4819, https://doi.org/10.1175/JCLI-D-14-00656.1, 2015.

Stevens, B. and Feingold, G.: Untangling aerosol effects on clouds and precipitation in a buffered system, Nature, 461, 607-613, 2009.

Stier, P., Schutgens, N. A. J., Bellouin, N., Bian, H., Boucher, O., Chin, M., Ghan, S., Huneeus, N., Kinne, S., Lin, G., Ma, X., Myhre, G., Penner, J. E., Randles, C. A., Samset, B., Schulz, M., Takemura, T., Yu, F., Yu, H., and Zhou, C.: Host model uncertainties in aerosol radiative forcing estimates: results from the AeroCom Prescribed intercomparison study, Atmos. Chem. Phys., 13, 3245-3270, https://doi.org/10.5194/acp-13-3245-2013, 2013.

Storelvmo, T., Lohmann, U., and Bennartz, R.: What governs the spread in shortwave forcings in the transient IPCC AR4 models?, Geophys. Res. Lett., 36, L01806, https://doi.org/10.1029/2008GL036069, 2009.

Sullivan, S. C., Lee, D., Oreopoulos, L., and Nenes, A.: Role of updraft velocity in temporal variability of global cloud hydrometeor number, Proc. Natl. Acad. Sci. USA, 113, 5791-5796, https://doi.org/10.1073/pnas.1514039113, 2016.

Taylor, K. E., Stouffer, R. J., and Meehl, G. A.: An Overview of CMIP5 and the Experiment Design, B. Am. Meteorol. Soc., 93, 485-498, https://doi.org/10.1175/BAMS-D-11-00094.1, 2012.

Telford, P. J., Braesicke, P., Morgenstern, O., and Pyle, J. A.: Technical Note: Description and assessment of a nudged version of the new dynamics Unified Model, Atmos. Chem. Phys., 8, 17011712, https://doi.org/10.5194/acp-8-1701-2008, 2008.

Tett, S. F. B., Rowlands, D. J., Mineter, M. J., and Cartis, C.: Can Top-Of-Atmosphere Radiation Measurements Constrain Climate Predictions? Part II: Climate Sensitivity, J. Climate, 26, 93679383, https://doi.org/10.1175/JCLI-D-12-00596.1, 2013.

Textor, C., Schulz, M., Guibert, S., Kinne, S., Balkanski, Y., Bauer, S., Berntsen, T., Berglen, T., Boucher, O., Chin, M., Dentener, F., Diehl, T., Easter, R., Feichter, H., Fillmore, D., Ghan, S., Ginoux, P., Gong, S., Grini, A., Hendricks, J., Horowitz, L., Huang, P., Isaksen, I., Iversen, I., Kloster, S., Koch, D., Kirkevåg, A., Kristjansson, J. E., Krol, M., Lauer, A., Lamarque, J. F., Liu, X., Montanaro, V., Myhre, G., Penner, J., Pitari, G., Reddy, S., Seland, Ø., Stier, P., Takemura, T., and Tie, X.: Analysis and quantification of the diversities of aerosol life cycles within AeroCom, Atmos. Chem. Phys., 6, 1777-1813, https://doi.org/10.5194/acp-6-17772006, 2006.

Textor, C., Schulz, M., Guibert, S., Kinne, S., Balkanski, Y., Bauer, S., Berntsen, T., Berglen, T., Boucher, O., Chin, M., Dentener, F., Diehl, T., Feichter, J., Fillmore, D., Ginoux, P., Gong, S., Grini, A., Hendricks, J., Horowitz, L., Huang, P., Isaksen, I. S. A., Iversen, T., Kloster, S., Koch, D., Kirkevåg, A., Kristjansson, J. E., Krol, M., Lauer, A., Lamarque, J. F., Liu, X., Montanaro, V., Myhre, G., Penner, J. E., Pitari, G., Reddy, M. S., Seland, Ø., Stier, P., Takemura, T., and Tie, X.: The effect of harmonized emissions on aerosol properties in global models an AeroCom experiment, Atmos. Chem. Phys., 7, 4489-4501, https://doi.org/10.5194/acp-7-4489-2007, 2007. 
Toll, V., Christensen, M., Gassó, S., and Bellouin, N.: Volcano and ship tracks indicate excessive aerosol-induced cloud water increases in a climate model, Geophys. Res. Lett., 44, 1249212500, https://doi.org/10.1002/2017GL075280, 2017.

Tost, H., Lawrence, M. G., Brühl, C., Jöckel, P., The GABRIEL Team, and The SCOUT-O3-DARWIN/ACTIVE Team: Uncertainties in atmospheric chemistry modelling due to convection parameterisations and subsequent scavenging, Atmos. Chem. Phys., 10, 1931-1951, https://doi.org/10.5194/acp-101931-2010, 2010.

Tsigaridis, K., Daskalakis, N., Kanakidou, M., Adams, P. J., Artaxo, P., Bahadur, R., Balkanski, Y., Bauer, S. E., Bellouin, N., Benedetti, A., Bergman, T., Berntsen, T. K., Beukes, J. P., Bian, H., Carslaw, K. S., Chin, M., Curci, G., Diehl, T., Easter, R. C., Ghan, S. J., Gong, S. L., Hodzic, A., Hoyle, C. R., Iversen, T., Jathar, S., Jimenez, J. L., Kaiser, J. W., Kirkevåg, A., Koch, D., Kokkola, H., Lee, Y. H., Lin, G., Liu, X., Luo, G., Ma, X., Mann, G. W., Mihalopoulos, N., Morcrette, J.-J., Müller, J.-F., Myhre, G., Myriokefalitakis, S., Ng, N. L., O’Donnell, D., Penner, J. E., Pozzoli, L., Pringle, K. J., Russell, L. M., Schulz, M., Sciare, J., Seland, Ø., Shindell, D. T., Sillman, S., Skeie, R. B., Spracklen, D., Stavrakou, T., Steenrod, S. D., Takemura, T., Tiitta, P., Tilmes, S., Tost, H., van Noije, T., van Zyl, P. G., von Salzen, K., Yu, F., Wang, Z., Wang, Z., Zaveri, R. A., Zhang, H., Zhang, K., Zhang, Q., and Zhang, X.: The AeroCom evaluation and intercomparison of organic aerosol in global models, Atmos. Chem. Phys., 14, 10845-10895, https://doi.org/10.5194/acp-1410845-2014, 2014.

van der Werf, G. R., Randerson, J. T., Giglio, L., Collatz, G. J., Mu, M., Kasibhatla, P. S., Morton, D. C., DeFries, R. S., Jin, Y., and van Leeuwen, T. T.: Global fire emissions and the contribution of deforestation, savanna, forest, agricultural, and peat fires (1997-2009), Atmos. Chem. Phys., 10, 11707-11735, https://doi.org/10.5194/acp-10-11707-2010, 2010.

Vehkamäki, H., Kulmala, M., Napari, I., Lehtinen, K. E. J., Timmreck, C., Noppel, M., and Laaksonen, A.: An improved parameterization for sulfuric acid-water nucleation rates for tropospheric and stratospheric conditions, J. Geophys. Res., 107, D22, https://doi.org/10.1029/2002JD002184, 2002.

Vergara-Temprado, J., Murray, B. J., Wilson, T. W., O’Sullivan, D., Browse, J., Pringle, K. J., Ardon-Dryer, K., Bertram, A. K., Burrows, S. M., Ceburnis, D., DeMott, P. J., Mason, R. H., O'Dowd, C. D., Rinaldi, M., and Carslaw, K. S.: Contribution of feldspar and marine organic aerosols to global ice nucleating particle concentrations, Atmos. Chem. Phys., 17, 3637-3658, https://doi.org/10.5194/acp-17-3637-2017, 2017.
Villarini, G. and Vecchi, G. A.: Projected increases in North Atlantic tropical cyclone intensity from CMIP5 models, J. Climate, 26, 3231-3240, https://doi.org/10.1175/JCLI-D-12-00441.1, 2013.

Welch, B. L.: The generalization of "Student's" problem when several different population variances are involved, Biometrika, 34, 28-35, https://doi.org/10.1093/biomet/34.1-2.28, 1947.

West, R. E. L., Stier, P., Jones, A., Johnson, C. E., Mann, G. W., Bellouin, N., Partridge, D. G., and Kipling, Z.: The importance of vertical velocity variability for estimates of the indirect aerosol effects, Atmos. Chem. Phys., 14, 6369-6393, https://doi.org/10.5194/acp-14-6369-2014, 2014.

Wilcox, L. J., Highwood, E. J., Booth, B. B. B., and Carslaw, K. S.: Quantifying sources of inter-model diversity in the cloud albedo effect, Geophys. Res. Lett., 42, 1568-1575, https://doi.org/10.1002/2015GL063301, 2015.

Williamson, D., Goldstein, M., Allison, L., Blaker, A., Challenor, P., Jackson, L., and Yamazaki, K.: History matching for exploring and reducing climate model parameter space using observations and a large perturbed physics ensemble, Clim. Dynam., 41, 1703-1729, https://doi.org/10.1007/s00382-013-1896-4, 2013.

Yoshioka, M., Regayre, L. A., Pringle, K. J., Johnson, J. S., Mann, G. W., Partridge, D., Stier, P., Kipling, Z., Bellouin, N., Sexton, D. M. H., Lister, G. M. S., Browse, J., Booth, B. B. B., Johnson, C. E., Johnson, B., Mollard, J. D. P., and Carslaw, K. S.: Ensembles of global climate model variants for the quantification and constraint of uncertainty in aerosols and their radiative forcing, J. Adv. Model. Earth Sy., in prep., 2018.

Zhang, S., Wang, M., Ghan, S. J., Ding, A., Wang, H., Zhang, K., Neubauer, D., Lohmann, U., Ferrachat, S., Takeamura, T., Gettelman, A., Morrison, H., Lee, Y., Shindell, D. T., Partridge, D. G., Stier, P., Kipling, Z., and Fu, C.: On the characteristics of aerosol indirect effect based on dynamic regimes in global climate models, Atmos. Chem. Phys., 16, 2765-2783, https://doi.org/10.5194/acp-16-2765-2016, 2016.

Zhao, C., Liu, X., Qian, Y., Yoon, J., Hou, Z., Lin, G., McFarlane, S., Wang, H., Yang, B., Ma, P.-L., Yan, H., and Bao, J.: A sensitivity study of radiative fluxes at the top of atmosphere to cloudmicrophysics and aerosol parameters in the community atmosphere model CAM5, Atmos. Chem. Phys., 13, 10969-10987, https://doi.org/10.5194/acp-13-10969-2013, 2013. 